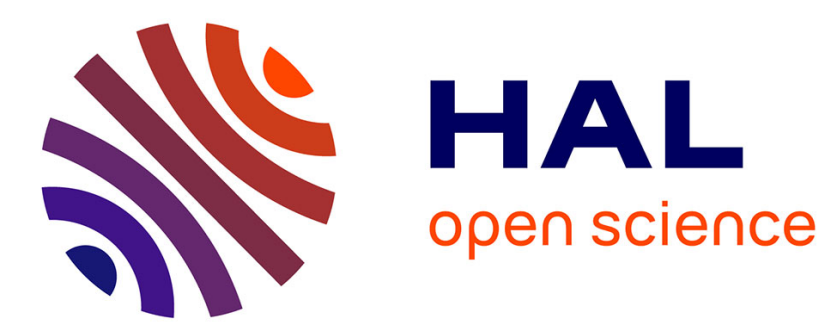

\title{
A roadmap to high-resolution standard microcoil MAS NMR spectroscopy for metabolomics
}

\author{
Alan Wong
}

\section{To cite this version:}

Alan Wong. A roadmap to high-resolution standard microcoil MAS NMR spectroscopy for metabolomics. NMR in Biomedicine, 2022, pp.e4683. 10.1002/nbm.4683 . cea-03509128

\section{HAL Id: cea-03509128 https://hal-cea.archives-ouvertes.fr/cea-03509128}

Submitted on 4 Jan 2022

HAL is a multi-disciplinary open access archive for the deposit and dissemination of scientific research documents, whether they are published or not. The documents may come from teaching and research institutions in France or abroad, or from public or private research centers.
L'archive ouverte pluridisciplinaire HAL, est destinée au dépôt et à la diffusion de documents scientifiques de niveau recherche, publiés ou non, émanant des établissements d'enseignement et de recherche français ou étrangers, des laboratoires publics ou privés. 
4 A roadmap to high-resolution standard microcoil MAS NMR spectroscopy 5 for metabolomics

6

7

8

$9 \quad$ Alan Wong

10

11 NIMBE, CEA, CNRS, Université Paris-Saclay, CEA Saclay, 91191 Gif-sur-Yvette, France; 12

corresponding author: alan.wong@,cea.fr, +33 (0) 148254054

14

15

16 Word count: 8727

17

18

19 


\section{Abstract}

21 The current microcoil probe technology has emerged as a significant advancement in NMR applications to biological research of biofluids and continued to excel as a hyphenated tool with other prominent microdevices opening many new possibilities in multiple omics fields.

24 However, this is contrary to biological samples like intact tissue or organism. This is due to 25 the considerable challenges of incorporating the microcoil in a magic-angle spinning (MAS) 26 probe without relinquishing the acquisition of high-resolution spectral data. Not until 2012, a microcoil MAS probe had shown promises on profiling the metabolome in submilligram tissue biopsy with spectral resolution on par with the conventional high-resolution MAS (HR-MAS) NMR. This result had subsequently triggered a great interest in the possibility of NMR analysis with microgram tissues and strived toward the probe development of 'highresolution' capable microcoil MAS NMR spectroscopy. This review gives an overview of the issues and challenges in the probe development and summarizes the advancements toward metabolomics.

Keywords: microcoil; magic-angle spinning; high-resolution; sensitivity; metabolomics;

\section{Selected Abbreviations}

magnetic susceptibility factor

40

$\mu$

micro

magnetic field

$42 \quad B_{0}$

external applied magnetic field

$43 \quad B_{1}$

transverse radiofrequency magnetic field

$44 \quad B_{z}$

dipole field of a magnetic moment

45 DNP

dynamic nuclear polarization

46 FWHM

full-width at half-maximum

electrical current

48 HMQC

heteronuclear multiple quantum coherence

high-resolution magic-angle spinning

$50 \quad \mathrm{rf}$ radiofrequency

51 SNR signal-to-noise ratio 


\section{Introduction}

54 Metabolomics is a significant omics field that studies the chemical fingerprints of small molecule metabolites that responds to specific cellular processes. It plays a vital role in untangling many complexities in life science. This is thanks to the vast advancement in bioanalytical technology. Ex vivo NMR spectroscopy has found tremendous success due to its simplicity and versatility in acquiring unbiased and rich metabolic information on diverse biospecimens from biofluids to biotissues. In particular, High-Resolution Magic-Angle Spinning (HR-MAS) - rapid sample spinning under a magnetic field - is an indispensable technique in NMR studies of animal and human tissue. ${ }^{1-7}$ This is attributed to its ability to acquire superior spectral resolution data from heterogeneous specimens (i.e., on par with the liquid state NMR). However, despite its significant applications to NMR-based metabolomics, the probe technology of HR-MAS has remained nearly the same in the past decades. The latest substantial advancement would be the fully automated HR-MAS probe (iProbe $^{\mathrm{TM}}$ ) in $2018 .{ }^{8}$ In contrast, other bioanalytical technologies like mass spectrometry (MS), ${ }^{9}$ magnetic resonance imaging, ${ }^{10}$ and positron emission tomography ${ }^{11}$ continue advancing. There is a common conception that the current number of MS-based metabolomic studies has overtaken NMR. ${ }^{12}$ A literature search in Web of Science ${ }^{\mathrm{TM}}$ shows a nearly 2:1 ratio between MS and NMR metabolomics. Therefore, for NMR spectroscopy to continue to be a frontline ex vivo analytic platform, new technologies and concepts should be explored entirely to address the limitations.

Presently, there is a general tendency to develop biotechnology toward microscopic specimens. The notion is to advance the underlining omics understanding at a single-cell (or even subcellular) level. ${ }^{13}$ One weakness in NMR spectroscopy is the inherent low detection sensitivity. The HR-MAS application generally requires 5-10 mg samples to compensate for the low sensitivity. This hinders the possibility of analyzing $\mu \mathrm{g}$ samples. Indeed, using a high magnetic field is an approach to enhance detection sensitivity. However, the running cost is exponential with the field. A cost-effective method is to utilize a miniature radiofrequency (rf) coil, so-called microcoil ( $\mu$ coil), for optimizing the sample and coil volume ratio (i.e., filling factor). The prime concern is maintaining high spectral resolution data to allow indepth metabolic profiling. This is achieved in liquid-state NMR by surrounding the microcoil 
zero-susceptibility $\mu$ coil. ${ }^{15}$ These adaptations have subsequently led to significant advancements in microcoil applications to biofluid studies. ${ }^{16}$

The fact that nano-scale volume of tissue and cell can be optimally detected and analyzed with a cost-effective approach makes $\mu$ coil an appealing technology. However, the $\mu$ coil technology under MAS, or microcoil MAS, is lagging. This is due to the challenges of implementing a stable $\mu$ coil that can endure a rapid sample spinning. The early designs centered on implanting an independent microcoil onto a conventional MAS probe and utilizing the existing stator to propel the sample spinning. The first microcoil under MAS was introduced in 2006 with a piggyback design ${ }^{17}$ and was shortly followed by an inductive spinning $\mu$ coil approach. ${ }^{18}$ These results had subsequently sparked the interest in the commercial and academic groups and have resulted in multiple commercial probes with rotor diameters ranging from 1-mm down to 0.5-mm. ${ }^{19-21}$ These state-of-the-art probes are explicitly designed to spin mg-scale samples up to $100+\mathrm{kHz}$ to narrow the resonance linewidth that arises from the nuclear spin networks. As a result, they have an immediate impact on the MAS applications in many research fields of biosolids, ${ }^{22-28}$ including the study of membrane proteins ${ }^{29}$ and amyloid fibers. ${ }^{30}$ However, the ultra-fast sample spinning is not of concern in the metabolomic study of delicate samples like tissues and cells. It is considered an unfavorable condition because of the enormous centrifugal force exerted on the sample. A significant concern in designing a microcoil probe for metabolomics is its ability to acquire sufficient spectral resolution data to unfold the dense metabolic ${ }^{1} \mathrm{H}$ resonance pattern and permit thorough peak analyses for identification and quantification. Moreover, the ability to acquire reproducible data is also a crucial factor. This depends on the stability of the probe and the consistency of the sample preparation for the NMR measurements.

\section{The possibility of ${ }^{1} \mathrm{H}$ NMR profiling $\mu \mathrm{g}$ biopsy tissue under MAS condition was first} evaluated in 2012. ${ }^{31}$ It subsequently triggered the interest of striving for the possibility of 'high-resolution' standard microcoil MAS toward NMR-based metabolomics. Despite the vast number of excellent review literature on HR-MAS NMR spectroscopy, ${ }^{1-3}$ microcoil NMR, ${ }^{16}$ and microcoil MAS, ${ }^{22-30}$ there are none on the 'high-resolution' standard microcoil MAS. Hence, this review aims to bridge the high-resolution microcoil technology under MAS conditions with metabolomics and provides the fundamental basis for future advancements. It 
summarizes the current developments, emphasizing our efforts from a nonexistence state to a

118 beacon of possibility.

\section{NMR considerations}

121 NMR is a spectroscopic technique that characterizes the net magnetization $\boldsymbol{M}$ induced in a sample exposed to an external field $\boldsymbol{H}_{\boldsymbol{0}}$, which can be described by a magnetic susceptibility factor $\chi, \boldsymbol{M}=\chi \boldsymbol{H}_{0}$. The net magnetic field $\boldsymbol{B}_{\boldsymbol{0}}$ in a sample exposed to $\boldsymbol{H}_{\boldsymbol{0}}$ can be expressed as

$$
\boldsymbol{B}_{0}=\mu_{0}\left(\boldsymbol{H}_{0}+\boldsymbol{M}\right)=\mu_{0} \mu \boldsymbol{H}_{0}
$$

where $\mu_{0}$ is a permeability of free space, and $\mu=1+\chi$ is the permeability of the sample. $\chi$ is a dimensionless quantity that indicates the extent of the magnetization $\boldsymbol{M}$ in a sample under an external field. Several sources contribute to $\boldsymbol{M}$, which arise from the energy current within atoms, electrons, and nucleons. They are essentially responsible for an NMR resonance line intensity and shape. This review focuses only on the magnetizations that contribute to the resonance intensity and resolution. Note that in NMR and MRI, the external magnetic field is often denoted as $B_{0}$ rather than $H_{0}$; thereby, $B_{0}$ will be used hereafter.

Sensitivity. It is a hallmark problem for NMR and is attributed to the nuclear spin magnetization $M_{0}$. At thermal equilibrium, $M_{0}$ can be expressed by the Boltzmann distribution, for 1/2-spin nuclei,

$$
M_{0}=\frac{\gamma \hbar N}{2} \mathrm{P}, \text { where } \mathrm{P}=\frac{N_{\alpha}-N_{\beta}}{N} \equiv \tanh \left(\frac{\gamma \hbar B_{0}}{2 k_{B} T_{S}}\right)
$$

where $\gamma$ is the gyromagnetic ratio, $\hbar(h / 2 \pi)$ is the Plank's constant, $N$ is the total number of spins $\left(N_{\alpha}+N_{\beta}\right)$, and $\mathrm{P}$ is the nuclear polarization, $B_{0}$ is the applied external magnetic field, $k_{B}$ and $T_{s}$ is the Boltzmann's constant and the sample temperature. The intensity of a detected signal is proportional to the polarization. For example, at a typical NMR field of $11.7 \mathrm{~T}$ at an ambient temperature of $300 \mathrm{~K}$, only about $40 \mathrm{ppm}$ of protons are polarized. Such small polarization is the very reason for the inherently low detection sensitivity in NMR.

Aside from $M_{0}$, the signal intensity - quantified by a signal-to-noise ratio (SNR) - also depends on the instrumentations, which can be breakdown into a few distinct components: ${ }^{32}$

$$
S N R \propto\left[\gamma B_{0}\right]_{\begin{array}{l}
\text { oscillation } \\
\text { frequency }
\end{array}} \times\left[M_{0}\right]_{\text {magnetization }} \times\left[B_{1} / i\right] \underset{\text { efficiency }}{\text { coil }} \times\left[\frac{1}{\sqrt{T_{c} R_{c}}}\right]_{\begin{array}{c}
\text { thermal } \\
\text { noise }
\end{array}}
$$

147 The first two correspond to the oscillation and the polarized magnetization of the nuclear

148 spin. The $B_{1} / i$ term is defined as the transverse magnetic field $B_{1}$ per unit current associated 
with the rf efficiency inside the coil volume. The last term is the thermal noise ascribed from

150 the coil's temperature $T_{c}$ and resistance $R_{c}$. Essentially, the strategy for increasing the SNR is

151 by manipulating the individual components through physics and engineering. For example, a

152 common conception is to raise the external magnetic field $B_{0}$ to enhance the spin oscillation

153 and magnetization. Since the signal and noise increase as a square and a square root of

154 the $B_{0}$ field, therefore the overall SNR increases as $B_{0}^{3 / 2}$. The current highest commercial

155 NMR field is $28 \mathrm{~T}\left(1.2 \mathrm{GHz}\right.$ for $\left.{ }^{1} \mathrm{H}\right) \cdot{ }^{33}$ Further increases are expected to be challenging and

156 expensive to overcome the issues of field homogeneity and stability.

158 Other approaches include manipulating the spin magnetization $M_{0}$ by polarization transfer. It

159 involves transferring the polarization from nuclei with high magnetic moment to lower

160 magnetic moment nuclei, offering a gain in sensitivity corresponding to the ratio of their

161 gyromagnetic ratios, $\gamma_{\text {high }} / \gamma_{\text {lower. This }}$ is routinely applied in solid-state ${ }^{13} \mathrm{C}$ (or $\left.{ }^{29} \mathrm{Si}\right) \mathrm{NMR}$ pulse experiments by polarizing the ${ }^{13} \mathrm{C}$ spins with the neighboring ${ }^{1} \mathrm{H}$ and can gain up to a factor of $\sim 4\left(\gamma_{1 \mathrm{H}} / \gamma_{13 \mathrm{C}}\right)$. Similarly, the polarization transfer from the electron spin to nuclear spin can have a tremendous gain (up to $10^{4}-10^{5}$ ) because of the large Zeeman splitting in the electron spin. Such transfer enters the regime of hyperpolarization, where the spin polarization deviates from thermal equilibrium. This phenomenon between the electron and nuclear is known as Dynamic Nuclear Polarization (DNP). Academic and commercial researchers have invested tremendous efforts in integrating DNP with high-field NMR and MRI research. ${ }^{34-36}$ In liquids, dissolution-DNP has already been widely integrated with advanced spectroscopy and imaging experiments and has opened many new opportunities including in vivo applications. ${ }^{34}$

173 Other hyperpolarization schemes have also been considered and applied. For example, a brute force approach would be lowering the sample temperature to millikelvin in high magnetic fields. ${ }^{37}$ This is, of course, not feasible for biological samples like tissues and organisms.

176 Other schemes have found success in the bioapplications; these include optical pumping with noble gases $\left({ }^{129} \mathrm{Xe}\right)$ for sensing the biomolecule activities,${ }^{38}$ photochemically-induced DNP

178 (photo-CIDNP) for investigating protein folding and biomolecular interactions, ${ }^{39}$ and parahydrogen-induced-polarization (PHIP) for kinetic studies. ${ }^{40}$ A common characteristic of these schemes is the inclusion of chemical additives or so-called polarizing agents. 
182 An approach to gain SNR without polarizing agents is by reducing the electronic thermal noise with a cryogenically cooled rf detection coil. It requires a specific probe design, denoted as cryoprobe, allowing to reduce the operating temperature of the coil to around $20 \mathrm{~K}$ while keeping the sample at an ambient temperature. Cryoprobes have become routinely employed in liquid-state NMR application to biomolecular research. ${ }^{41}$ The coil is constructed with a superconducting wire, such as $\mathrm{YBa}_{2} \mathrm{Cu}_{3} \mathrm{O}_{7-\mathrm{d}}(\mathrm{YBCO})$, with zero resistance under 20 $30 \mathrm{~K}$, reducing the electronic noise and can lead to an SNR gain up to 4-5 folds. The use of a cold coil is of particular interest in the microcoil probe because of the increased noise level as the coil size decreases; therefore, it is logical to integrate the cryoprobe technology with the microcoil. Brey and his team ${ }^{42}$ have designed and constructed a high-resolution capable cryoprobe with a 1-mm coil for liquid-state NMR spectroscopy. The probe has an active sampling volume of $6.3 \mu \mathrm{L}$ with superconducting YBCO coils cooled to about $20 \mathrm{~K}$. The resultant mass sensitivity (SNR per unit mass) is more than 20 times higher than a standard 5$\mathrm{mm}$ probe. One of the engineering challenges in cryoprobe is implanting a sharp thermal gradient of a vacuum barrier between the confined space of the cold coil and the ambient sample without relinquishing the filling factor. This indeed has dramatically hindered the development of cryoprobes under MAS conditions. The first probe, so-called cyrocoil MAS, was introduced in 2008 designed and constructed by Mizuno with his team at JEOL, ${ }^{43}$ but only recently, a more accessible probe was released by Bruker (BioSolids CryoProbe ${ }^{\mathrm{TM}}$ ) and has found succussed in the biosolids. ${ }^{44}$ The notion of 'high-resolution' spectroscopy would hugely complicate the design and construction of a cyrocoil 'HR'-MAS probe. To this day, only one attempt has been made by Doty and his team. ${ }^{45}$

As these enhancement schemes require substantial instrumentation and operation costs, it is of interest to explore cost-effective alternatives. One approach is optimizing the technology in the rf coil efficiency, the $B_{1} / i$ term in Equation 3, by using rf microcoils.

Radiofrequency microcoil. Electronically, the rf coil - the closest probe component to the sample - functions as an inductive antenna that receives the voltage-induced $\mathrm{rf}$ transmitting

211 by the precession of the spin magnetization of the sample. The transverse rf magnetic field

212 efficiency, $B_{1} / i$, of an rf coil plays a role in SNR and has been discussed in detail by Hoult 213 and Richards, ${ }^{32}$ and reviewed by Webb. ${ }^{46}$ It implies that the SNR is inversely proportional to

214 the diameter of the saddle and solenoid coil; thus, the gain in sensitivity can be achieved by 
miniaturizing the coil around the small sample volume. Herein, we will focus on the solenoid coil. It has a cylindrical geometry by winding a long wire with multiple helical turns

217 producing an effectively strong and uniform transverse field inside the cylindrical volume.

218 The $B_{1} / i$ term in Equation 3 can be expressed using Biot-Savart law,

$$
\frac{B_{1}}{i}=\frac{n \mu_{0}}{2 r} \frac{1}{\sqrt{1+(l / 2 r)^{2}}}
$$

where $n$ is the number of helical turns, $r$ and $l$ are the radius and length of the solenoid coil, and $\mu_{0}$ is the permeability of the vacuum. Evidently, with a fixed $l / 2 r$ factor, $B_{1} / i$ increases with the inverse of the coil diameter. Minard and Wind have outlined a didactic guideline for designing $\mu$-size solenoids $(2 \mathrm{r} \leq 1-\mathrm{mm})$ with optimal $\mathrm{rf}$ performance. ${ }^{47,48}$ Sweedler and Webb and their team have exploited the simplicity of the solenoid design and demonstrated the possibility of acquiring high-quality ${ }^{1} \mathrm{H}$ NMR signals of nano-volume samples with coils less than 1-mm in diameter. ${ }^{14,49}$ This result has set off a substantial interest in academic and commercial research on microcoil probe technology and made significant advancements in studying volume/mass limited samples. There are several review literature on microcoil NMR spectroscopy. ${ }^{46,50-56}$ Indeed, the capability of analyzing small volumes makes it a natural choice for coupling with chemical microseparation techniques ${ }^{57}$ and with microfluidics. The latter includes an innovative hand-held NMR unit, referred to as diagnostic magnetic resonance (DMR), developed by Weissleder and his team. ${ }^{58}$ It integrates a microcoil with a microfluidic system to rapidly screen biospecimens such as bacteria and tumor cells by discriminating their transverse relaxation rates. This technique has recently advanced in conjunction with DNP, denoted as hyperpolarized micromagnetic resonance spectrometer (HMRS). ${ }^{59}$ It permits an ultra-high sensitivity detection for a real-time NMR analysis of the metabolic flux in living cells. The possibility of noninvasive monitoring with HMRS of tumor progression and treatment efficacy had been proposed to be tested in clinical trials. ${ }^{59} \mathrm{In}$ the commercial sectors, they have adapted a balance between sensitivity and sampling volume for a routine-based biomolecular study. For example, Bruker has incorporated a 1mm diameter coil with an active sampling volume of about $2.5 \mu \mathrm{L} .{ }^{60}$

243 Although the microcoil technology is well adapted in the NMR studies of biofluids and has continued to advance in novel applications, it is entirely different for samples under MAS (or microcoil MAS). This is due to the engineering challenges of implementing a microcoil inside a MAS stator that can endure a rapid sample spinning. The early developments (with coil diameter $\leq 1)$ are explicitly targeted on solid-state experiments. This is because of the 
considerable advantage of fast sample spinning experiments with small rotors and the strong $B_{1}$ field strength from the small coil. The first successful experiment was carried out in 2006 by Kentgens and his team using a so-called piggyback design. ${ }^{17}$ To overcome the challenge of implementing a microcoil, a standard 4-mm stator was used to spin a standard rotor piggybacking an $\mu$-size sampling capillary centered inside a microcoil coil cavity. This clever design permits a stable spinning of the sampling capillary driven by the conventional stator while enhancing the signal with a microcoil. The results had demonstrated the possibility of acquiring isotropic spectra on $\mu \mathrm{g}$ of solids and the $B_{l}$ efficiency of producing a strong decoupling $B_{1}$ field for line narrowing experiments.

In 2012, JEOL introduced the first commercial microcoil MAS probe with a $0.75-\mathrm{mm}$ stator, ${ }^{19}$ and shortly followed by Bruker countering with a $0.7-\mathrm{mm}$ probe. ${ }^{20}$ These probes are capable of sample spinning as high as $110 \mathrm{kHz}$, offering the possibility of suppressing the large nuclear spin magnetizations ascribed from the spin-interactions to yield narrow NMR lines for characterizing solids. Hence, these microcoil MAS probes are also known as ultrafast MAS. Recently, a research team has introduced a 0.5-mm MAS probe that offers a groundbreaking sample spinning at $170 \mathrm{kHz} .{ }^{21}$ These commercial ultrafast probes have now widened the NMR applications on biosolids, including ${ }^{1} \mathrm{H} \mathrm{NMR},{ }^{22-30}$ an area that was first considered impossible because of the intrinsically broad ${ }^{1} \mathrm{H}$ signals in biosolids.

The extensive developmental works in the ultrafast MAS probe have been primarily focused on increasing the sample spinning and the rf field efficiency and reducing the sample heating ascribed to the rotor friction and $\mathrm{rf}$. There is little attention on the line broadening caused by the static probe materials, which sample rotation cannot suppress. Consequently, the optimal line resolution from these probes is insufficient for ${ }^{1} \mathrm{H}$ metabolic investigation on samples like tissue biopsy. Most ultrafast MAS probes offer $0.01-0.02 \mathrm{ppm}$ linewidth at best and often with a distorted lineshape that field shimming cannot correct.

Line resolution. To comprehend the source of the line-width and -shape of an NMR resonance, one must understand the origins of the effective field $\boldsymbol{B}$ experienced by the sample (Equation 1), which depends on the susceptibility factor $\chi$ arising from the local dipole magnetic moment $m$. For example, when a metabolite is immersed in an isotropic solution, its susceptibility induces an additional field upon the metabolite and results in a resonance shift. 
However, metabolites in a complex biological medium are usually distributed in different cellular compartments and morphologies, each with a different susceptibility field.

283 Consequently, this creates a heterogenous field for the metabolic protons to resonate at a series of varying resonance shifts resulting in line broadening. In NMR, this is known as magnetic susceptibility broadening.

Several convenient approaches to numerically determining the susceptibility fields inside and outside volumes of different shapes. ${ }^{61,62}$ One approach divides the local medium into finite volume elements and the sum of all the different magnetic dipole field contributions. In a simple case of small $\chi \leq 1$ (as in most samples), the dipole field $B_{z}$ can be expressed by an angular dependence function,

$$
B_{z}(\theta, r)=\frac{\mu_{0} m\left(3 \cos ^{2} \theta-1\right)}{r^{3}}
$$

293 where $m$ is the individual magnetic moment, $\theta$ is the angle of the dipole vector to $B_{0}$, and $r$ is the distance apart. Note that $B_{\mathrm{z}}$ determines the resonance shift, which leads to line broadening, in the nuclear Larmor frequency induced by $m$, but it vanishes in the far distant field or along the surface of a magic-angle cone, $\cos ^{-1}(1 / \sqrt{3})=54.74^{\circ}$ to the external field. This angle is significant for line-narrowing, which will be covered in a later section. A simple numerical estimation of the $B_{z}$ field can be deduced using an ideal spherical model (Figure 1a), where a magnetized sphere with a radius of $a$ and a permeability $\mu_{\text {sphere }}=1+\chi_{\text {sphere }}$ submerged in a sample with $\mu_{\text {sample }}=1+\chi_{\text {sample. The different dipole fields dispersed outside }}$ the magnetized sphere can be simplified as,

$$
B_{z}(\theta, r) \approx-\frac{\Delta \chi}{3} \frac{a^{3}}{r^{3}} B_{0}\left(3 \cos ^{2} \theta-1\right)
$$

where $\Delta \chi=\chi_{\text {sample }}-\chi_{\text {sphere. }}$ For example, the resonance frequency of the water molecules $(\chi$ $=-9 \times 10^{-6}$ SI unit, the negative value indicates diamagnetism) in a water bath containing a spherical air bubble $(\chi \approx 0)$ can shift as high as $6 \mathrm{ppm}$ when $r=a$. This shift decreases as $r$ increases, say to $3 a$; the shift is about $1.3 \mathrm{ppm}$, in-line with a typical linewidth of the water resonance. A similar effect can be found in the metabolite protons residing around the

310 Another source of the $B_{z}$ field is from the nearest probe components, which can be significant 311 in the $\mu$-size probe, where the entire sample volume is only a submillimeter apart from the magnetized materials such as the microcoil. For example, Webb and Grant ${ }^{63}$ have shown a 
313 threefold increase in the linewidth when a nano-volume sample is centered inside the

314 solenoid with only 50- $\mu \mathrm{m}$ apart from the microcoil.

316 There are several approaches to suppress $B_{z}$ ascribed to the coil. These include the use of a 317 zero-susceptibility wire. It is a copper-alloy with a positive susceptibility metal, such as 318 aluminum $\left(\chi=+20.9 \times 10^{-6}\right)^{64}$ or rhodium $\left(\chi=+168 \times 10^{-6}\right),{ }^{65}$ to cancel the negative

319 susceptibility contribution of the copper. However, the cost of manufacturing zero320 susceptibility wire is high because of the difficulty in producing precise and reproducible doping content with small diameter wires. An academic group has proposed a laboratory method of constructing a zero-susceptibility coil using a hollow copper capillary filled with a specific concentration of a paramagnetic solution $\mathrm{NiSO}_{4}$ neutralizing the negative susceptibility of copper. ${ }^{66}$

Another approach to minimize the $B_{z}$ effects is to surround the microcoil with a cylindrical medium of matching susceptibility creating an infinite long uniform field around the sample to facilitate the field shimming. The medium can be a perfluorinated fluid such as FC-43 ( $\chi=$ $\left.-8.8 \times 10^{-6}\right),{ }^{14}$ or an epoxy solid doped with a specific content of positive susceptibility paramagnetic ions. ${ }^{67,68}$ The simplicity of these methods has accelerated the academic research on microcoil in liquid-state NMR for producing high-resolution spectral data.

Magic-angle spinning. As stated in Equation 5, the angular dependence $B_{z}$ field vanishes when the dipole vector from the magnetic moment aligns with an axis at an angular distance of $54.74^{\circ}$ to the external field. The angle is known as the magic-angle. This, in turn, suggests that spinning a sample at a magic-angle would eliminate the $B_{z}$ field, suppressing the susceptibility broadening. This was first demonstrated in the early work of Garroway ${ }^{69}$ with liquid samples and later discussed by Barbara ${ }^{70}$ in detail of the demagnetization fields inside the small volume cylindrical samples $(40 \mu \mathrm{L})$ at magic-angle, so-called the magic-angle cylinder. This essentially marked the beginning of the high-resolution standard magic-angle spinning technique, widely known as 'HR'-MAS. An extensive description of the theoretical and hardware of HR-MAS NMR can be found in ref 71 and 72. As illustrated in Figure 1b, when the sample rotates along the axis of magic-angle $\theta_{M A}$, the angle $\delta$ and the azimuth angle $\phi$ become a time-dependent component given as:

$$
\cos \delta(t)=\cos \beta \cos \theta_{M A}+\sin \beta \sin \theta_{M A} \cos (\phi(t))
$$


where $\beta$ is the angular separation between the sample rotation axis and the directional dipole $\mathrm{D}_{\mathrm{r}}$, and $\phi$ is the azimuth angle on the plane perpendicular to the rotation axis. Integrating the above Equation 7 with 5, the resultant $B_{z}$ field of a rotating sample becomes

$$
B_{z}=\frac{\mu_{0} m}{2 r^{3}}\left\{\begin{array}{l}
\left(3 \cos ^{2} \beta-1\right)\left(3 \cos ^{2} \theta_{M A}-1\right)+ \\
3 \sin 2 \beta \sin 2 \theta_{M A} \cos \left(\omega_{r} t+\phi\right)+ \\
3 \sin ^{2} \beta \sin ^{2} \theta_{M A} \cos \left(2\left(\omega_{r} t+\phi\right)\right)
\end{array}\right\}
$$

where $\omega_{r}$ is the sample rotation frequency. When $\theta_{M A}=54.74^{\circ}$, the first term vanishes, leaving the second and third terms as the spinning-sideband signals that appear at multiple amplitude periods depending on the static linewidth of $\omega_{r}=0$. Subsequently, MAS eliminates the susceptibility broadening $B_{z}$ at rapid spinning and results in isotropic resonances at chemical shifts depending on the induced field driven by the chemical shielding. MAS also eliminates - partially in some cases - other local susceptibility fields ascribe from the spin interactions, such as spin-spin dipole, anisotropic chemical shift, and quadrupole. These interactions can contribute up to $\mathrm{kHz}-\mathrm{MHz}$ in linewidth for solids. Therefore, fast sample rotation is imperative to characterize the local spin environments in solid materials.

In the context of 'HR'-MAS, it is essential to note that MAS does not eliminate the susceptibility $B_{z}$ fields ascribed from the probe materials outside the rotating sample. For a standard solid-state 4-mm MAS probe, the coil and stator (the closest components to the sample) are about 1-2 $\mathrm{mm}$ apart from the sample located at the wall of the rotor. This contributes to some degree of unsuppressed line broadening with the MAS. This is evident by the skew baseline for each resonance acquired from a conventional 4-mm MAS probe (Figure 2). For microcoil MAS, the entire sample volume is merely a few hundredth microns apart from the coil, which renders a significant $B_{z}$ field and gives substantial broadening. An example has been illustrated by an early attempt to profile a $150 \mu \mathrm{g}$ muscle tissue using a sub-microcoil 1.6-mm MAS at $21 \mathrm{~T} .{ }^{73}$ Despite the excellent sensitivity, it is obtained at the cost of susceptibility broadening from the probe materials and obscured the J-splitting for metabolic identifications. As a result, only the lipid signals could be confidently identified. Unquestionably, the first of many challenges in the microcoil MAS development toward metabolomic applications is to achieve sufficient high spectral resolution without sacrificing the sensitivity $B_{1} / i$.

\section{Toward high-resolution standard microcoil MAS}


378 Since the first demonstration of high-resolution standard MAS on liquid samples, ${ }^{69,70}$

379 academic and commercial groups have invested extensive resources in developing HR-MAS

380 probes to advance its application with high data reproducibility, user feasibility, and

381 accessibility. As a result, HR-MAS has become the principal technique in ex vivo NMR

382 studies of specimens like pathological biopsies. ${ }^{1-7}$ On the contrary, the development of high-

383 resolution capable microcoil MAS is scarce. The first attempt on the submilligram sample

384 was with a bovine tissue $(\sim 300 \mu \mathrm{g})$ using a spinning microcoil in $2007 .{ }^{18}$ But, it was not until

3852012 that an evaluation was made on profiling the metabolome on human tissue $(<500 \mu \mathrm{g}){ }^{31}$

386 The results demonstrated a gain in sensitivity via the microcoil, but the ${ }^{1} \mathrm{H}$ line resolution was

387 insufficient for metabolic profiling. Regardless, the results rendered a realization of an NMR

388 application on $\mu$ g-scale tissues with microcoil MAS.

389

390 The technological issues and challenges for developing a microcoil MAS probe with a 'high-

391 resolution' capability are different than those for a microcoil (or ultrafast) MAS probe. While

392 faster sample spinning, stronger rf field, and reducing the frictional and electrical heating are

393 the prime interests in the ultrafast probe developments, the high-resolution probe focuses on

394 the high spectral resolution (down to ppb) capability with good feasibility and data

395 reproductivity and reliability. As expected, the complication in the microcoil probe

396 development is the complexity of handling the small size materials. A slight deviation or

397 error from the ideal condition - whether in the probe materials, microcoil, or NMR sample

398 preparation - will magnify its effect on the NMR performance and, therefore, on the spectral

399 resolution. To this day, the development of high-resolution standard microcoil MAS is still in

400 its infancy, and only proof-of-concept studies have been reported (Table 1).

401

402 Table 1. A chronological list of the significant developments that have led to 'HR' standard

403 microcoil MAS NMR

\begin{tabular}{|c|c|c|c|}
\hline Year & $\begin{array}{l}\text { Microcoil condition } \\
\text { (active coil volume) }^{\mathrm{a}}\end{array}$ & Highlight & Result $^{\mathbf{b}}$ \\
\hline $2006^{[17]}$ & $\begin{array}{l}\text { Static } \\
\text { (vary; sample volume } \\
\text { down to } 10 \mathrm{~nL} \text { ) }\end{array}$ & $\begin{array}{l}\text { Introduced the first microcoil } \\
\text { MAS probe: piggyback design }\end{array}$ & $\begin{array}{l}\text {-A } \mu \text { g sample capillary is piggybacked } \\
\text { on a standard rotor } \\
\text {-Enhanced } B_{1} / i \text { via the } \mu \text { coil } \\
\text {-Demonstrated the possibility of } \mu \mathrm{g} \\
\text { sample analysis }\end{array}$ \\
\hline $2007^{[18]}$ & $\begin{array}{l}\text { Spinning } \\
(\text { vary }<900 \mathrm{~nL})\end{array}$ & $\begin{array}{l}\text { Introduced an inductive } \\
\text { spinning resonator: MACS }\end{array}$ & $\begin{array}{l}\text {-An inductive resonator is placed inside } \\
\text { a standard MAS rotor } \\
\text {-Enhanced } B_{1} / i \text { via the inductive } \\
\text { resonator; a mass-sensitivity of } 46 \\
\mathrm{mg}^{-1} \text { is found for } 750-\mu \mathrm{m} \text { MACS }\end{array}$ \\
\hline
\end{tabular}




\begin{tabular}{|c|c|c|c|}
\hline $2012^{[31]}$ & $\begin{array}{l}\text { Spinning } \\
(570 \mathrm{~nL})\end{array}$ & $\begin{array}{l}\text { Evaluated the }{ }^{1} \mathrm{H} \text { profiling with } \\
\mu \mathrm{g} \text { biopsy using MACS }\end{array}$ & $\begin{array}{l}\text {-Carried out on an } 870 \text { - } \mu \mathrm{m} \text { diameter } \\
\text { resonator with }<500 \mu \mathrm{g} \text { tissue } \\
\text {-A } 17 \text {-fold mass sensitivity } \\
\text { enhancement compared to HR-MAS } \\
\text {-Insufficient }{ }^{1} \mathrm{H} \text { resolution }(0.01 \mathrm{ppm}) \\
\text {-Demonstrated the high versatility } \\
\text {-Difficult in coil fabrication with no } \\
\text { reproductivity }\end{array}$ \\
\hline $2012^{[75]}$ & $\begin{array}{l}\text { Spinning } \\
(500 \mathrm{~nL})\end{array}$ & $\begin{array}{l}\text { Introduced an automated } \\
\text { fabrication of MACS: on-chip } \\
\text { MACS }\end{array}$ & $\begin{array}{l}\text {-Carried out on a } 1000-\mu \mathrm{m} \text { diameter } \\
\text { resonator } \\
\text {-Eased the fabrication with a robotic } \\
\text { wire-binding technology; } \sim 100 \\
\text { resonators per production } \\
\text {-Poor line resolution }(1 \mathrm{ppm}) \text { ascribed } \\
\text { to the large susceptibility gradient } \\
\text { from the gold wire solenoid } \\
\text {-Demonstrated the possibility of mass- } \\
\text { manufactured resonators }\end{array}$ \\
\hline $2013^{[73]}$ & $\begin{array}{l}\text { Static } \\
(19300 \mathrm{~nL})\end{array}$ & $\begin{array}{l}\text { Attempt on }{ }^{1} \mathrm{H} \text { profiling of } \mu \mathrm{g}- \\
\text { tissue using a standard MAS } \\
\text { probe }\end{array}$ & $\begin{array}{l}\text {-Carried out on a 1.6-mm MAS with a } \\
150 \mu \mathrm{g} \text { tissue at } 21 \mathrm{~T} \\
\text {-Good sensitivity but with poor line } \\
\text { resolution due to the strong magnetic } \\
\text { susceptivity gradients from the stator } \\
\text { and coil }\end{array}$ \\
\hline $2013^{[76]}$ & $\begin{array}{l}\text { Spinning } \\
(200 \mathrm{~nL})\end{array}$ & $\begin{array}{l}\text { Refined the MACS design } \\
\text { (First 'HR'-capable microcoil } \\
\text { MAS) }\end{array}$ & $\begin{array}{l}\text {-Carried out on a } 550-\mu \mathrm{m} \text { diameter } \\
\text { resonator } \\
\text {-Offered excellent }{ }^{1} \mathrm{H} \text { resolution }(0.004 \\
\text { ppm) while retaining the sensitivity }\end{array}$ \\
\hline $2014^{[77]}$ & $\begin{array}{l}\text { Spinning } \\
\text { (vary: } 100-420 \mathrm{~nL} \text { ) }\end{array}$ & $\begin{array}{l}\text { A demonstrative metabolomic } \\
\text { study on submillimeter } \\
\text { organisms using HR-MACS } \\
\text { (First metabolomic NMR study } \\
\text { with nL volume under MAS) }\end{array}$ & $\begin{array}{l}\text {-First metabolomic NMR study with } \\
\text { microcoil MAS } \\
\text {-The model study was carried out with } \\
\text { an } 840-\mu \text { m diameter resonator with } \\
\text { samples of }<100 \text { C. elegans } \\
\text { individual } \\
\text {-Introduced the use of a single fixed } \\
\text { resonator with a sample-exchange } \\
\text { capillary for easing the sample } \\
\text { preparation } \\
\text {-Successfully carried out the }{ }^{1} \mathrm{H} \\
\text { metabolic profiling and } \\
\text { discrimination analysis of } C \text {. elegans } \\
\text {-Limited to small scale study due to } \\
\text { coil fragility } \\
\text {-Single worm detection was carried out } \\
\text { with a } 400 \text { - } \mu \text { m resonator }\end{array}$ \\
\hline $2015^{[78]}$ & $\begin{array}{l}\text { Static } \\
(<1500 \mathrm{~nL})\end{array}$ & $\begin{array}{l}\text { Introduced a 'high-resolution' } \\
\text { capable 1-mm microcoil MAS } \\
\text { probe: HR- } \mu \text { MAS }\end{array}$ & $\begin{array}{l}\text {-Modified from an ultrafast } 1-\mathrm{mm} \text { MAS } \\
\text { probe by replacing with a specific } \\
\text { design stator } \\
\text {-Despite the new stator, strong rf } \\
\text { shimming fields are needed to acquire } \\
\text { a good line resolution }(0.002 \mathrm{ppm}),\end{array}$ \\
\hline
\end{tabular}

-Insufficient ${ }^{1} \mathrm{H}$ line resolution for metabolic analysis

Carried out on an 870- $\mu \mathrm{m}$ diameter 17 -fold mass sensitivity enhancement compared to HR-MAS

-Insufficient ${ }^{1} \mathrm{H}$ resolution $(0.01 \mathrm{ppm})$

Demonstrated the high versatility

coil fabrication with no

fabrication of MACS: on-chip Eased the fabrication with a robotic wire-binding technology; 100 Poor line resolution (1 ppm) ascribed to the large susceptibility gradient manufactured resonator $150 \mu \mathrm{g}$ tissue at $21 \mathrm{~T}$

Good sensitivity but with poor line resolution due to the strong magnetic susceptivity gradients from the stator Carried out on a $550-\mu \mathrm{m}$ diameter nato $\mathrm{ppm}$ ) while retaining the sensitivity First metabolomic NMR study with The model study was carried out with an $840-\mu \mathrm{m}$ diameter resonator with samples of $<100$ C. elegans resonator with a sample-exchange capillary for easing the sample preparation

metabolic profiling and discrimination analysis of C. elegans coil fragility

Single worm detection was carried out

-Modified from an ultrafast 1-mm MAS probe by replacing with a specific design stator a good line resolution $(0.002 \mathrm{ppm})$ 


\begin{tabular}{|c|c|c|c|}
\hline $2018^{[79]}$ & $\begin{array}{l}\text { Static } \\
(<1500 \mathrm{~nL})\end{array}$ & $\begin{array}{l}\text {-A demonstrative study on } \mu \mathrm{g} \\
\text { food tissues using HR- } \mu \text { MAS }\end{array}$ & $\begin{array}{l}\text {-First metabolomic NMR study with } \\
\text { HR- } \mu \text { MAS with a model study of } \\
\mathrm{n}>30 \text { with } \sim 300 \mu \mathrm{g} \text { tissue } \\
\text {-Demonstrated a reliable metabolomic } \\
\text { study with multivariate analysis for } \\
\text { localizing the metabolic variances in } \\
\text { different anatomical tissues }\end{array}$ \\
\hline $2019^{[80]}$ & $\begin{array}{l}\text { Spinning } \\
(500 \mathrm{~nL})\end{array}$ & $\begin{array}{l}\text {-Refined the on-chip MACS } \\
\text { (Voxalytic }^{\mathrm{TM}} \text { MACS insert) }\end{array}$ & $\begin{array}{l}\text {-Replaced the original gold wire with } \\
\text { copper, resulting in a significant } \\
\text { improvement in line-resolution (from } \\
1 \text { to } 0.01 \text { ppm); but still inferior to } \\
\text { HR-MACS and HR- } \mu \text { MAS }\end{array}$ \\
\hline $2021^{[81]}$ & $\begin{array}{l}\text { Static } \\
(<1500 \mathrm{~nL})\end{array}$ & $\begin{array}{l}\text {-A demonstrative study on } \mu \mathrm{g} \\
\text { rodent tissues using HR- } \\
\mu \mathrm{MAS} \text { with a model study of } \\
\mathrm{n}>100 \\
\text { (First metabolomic study on } \mu \mathrm{g} \\
\text { tissue biopsy) }\end{array}$ & $\begin{array}{l}\text {-Spatial metabolic mapping on tumoral } \\
\text { brain slices } \\
\text {-The large-scale study with } \mathrm{n}>100 \text { of } \\
\sim 300 \mu \mathrm{g} \text { tissue illustrated the } \\
\text { capability of acquiring good } \\
\text { reliability and reproducibility spectral } \\
\text { data } \\
\text {-Delimited the tumor lesion using } \\
\text { multivariate analysis }\end{array}$ \\
\hline
\end{tabular}

suggesting the presence of magnetic susceptibility gradients

-Demonstrated the feasibility of 2D

${ }^{1} \mathrm{H}\left\{{ }^{13} \mathrm{C}\right\}$ HMQC experiment

-First metabolomic NMR study with HR- $\mu$ MAS with a model study of $\mathrm{n}>30$ with $\sim 300 \mu \mathrm{g}$ tissue study with multivariate analysis for localizing the metabolic variances in different anatomical tissues copper, resulting in a significant improvement in line-resolution (from 1 to $0.01 \mathrm{ppm}$ ); but still inferior to HR-MACS and HR- $\mu$ MAS

Spatial metabolic mapping on tumoral brain slices

The large-scale study with $\mathrm{n}>100$ of $\sim 300 \mu$ g tissue illustrated the capability of acquiring good reliability and reproducibility spectral

Delimited the tumor lesion using

were deduced from a sucrose

(a) Estimate

The first high-resolution capable microcoil MAS probe ${ }^{76}$ was a modification of an early success ultrafast microcoil probe, which used an inductively coupled spinning $\mu$-resonator, so-called magic-angle coil spinning (MACS). ${ }^{18}$ It is essentially a self-resonant solenoid coil wrapped closely around a nano-volume capillary and is secured inside a standard large MAS rotor. The setup renders an ensemble spinning to suppress the susceptibility $B_{z}$ fields from the rotating microcoil and the sample and gain sensitivity via the inductively coupled microcoil. One advantage of MACS is the resonator's dimensions versatility. It enables tailoring the active and sample volume to accommodate the optimum filling factor. However, the spinning of a coil under a magnetic field inherently generates an eddy current within the conductive wire, producing heat via the dissipated power. The power can be estimated by modeling a single rotating loop of a conductive wire, ${ }^{82}$

$$
P=\omega_{r}^{2} B^{2}\left(\frac{r h^{3} w}{\rho}\right)
$$

It depends on various factors: the effective magnetic field $(B)$, the rotating frequency $\left(\omega_{r}\right)$, the loop radius $(r)$, and the wire cross-section $(w)$, and its resistivity $(\rho)$. Any increase of these factors would lead to a rise in power and thus increase sample heating. This was evident with a microcoil constructed with a $62-\mu \mathrm{m}$ cross-section of a $\mathrm{Cu}$ wire, spinning at $6000 \mathrm{~Hz}$ 
inside an $11.7 \mathrm{~T}$ magnet; ${ }^{76}$ it heated the sample by $37^{\circ} \mathrm{C}$. In contrast, the heating decreased to $1.6{ }^{\circ} \mathrm{C}$ with a thinner $30-\mu \mathrm{m} \mathrm{Cu}$ wire; and it further reduced to $0.02{ }^{\circ} \mathrm{C}$ with a reduced spinning frequency to $500 \mathrm{~Hz}$. Indeed sample heating is of concern, not only to the integrity of the specimens, but it generates a temperature gradient throughout the sample volume and subsequently gives rise to line broadening caused by a series of frequency shifts in the resonance. ${ }^{83}$ The consequences can be severe for a water (HDO) sample since the ${ }^{1} \mathrm{H}$ chemical shift is temperature-dependence $-11.9 \mathrm{ppb} /{ }^{\circ} \mathrm{C} .{ }^{84}$ Figure 3 shows a dramatic loss of the sucrose anomeric proton line resolution as the spinning frequency increases. This is mainly attributed to the heating originating from the eddy current arising in the spinning $\mathrm{Cu}$ wire. For example, at a routine $5000 \mathrm{~Hz}$ spinning, it generates about $2{ }^{\circ} \mathrm{C}$, efficiently concealing a J-splitting of $4 \mathrm{~Hz}$. In contrast, a clear doublet is well resolved with low spinning $(<500 \mathrm{~Hz})$, but it gives rise to a dense spinning-sideband pattern in the spectrum (Equation 8), and requires suppression pulse experiments to disclose the isotropic resonances. The refined MACS design - thin wire coil with slow-spinning - to achieve high-resolution capable microcoil MAS is referred to as HR-MACS.

HR-MACS had shown an impressive spectral quality for profiling the metabolome with only 12-individuals of the submillimeter nematodes Caenorhabditis elegans (Figure 4). ${ }^{77}$ The spectral similarity to the large volume HR-MAS with more than 1000 individuals is unprecedented. It rendered the identification of a total of 31 metabolites, representing the most NMR-identified metabolites in a MAS spectrum of a nano-volume biological sample. The sensitivity enhancement with HR-MACS is 5-fold ( $\left.B_{1}^{H R M A C S} / B_{1}^{H R M A S}\right)$ higher than that with HR-MAS. In other words, it would require an acquisition period of $25 \times$ longer for HRMAS to obtain the same level of SNR as for HR-MACS with 12-individual worms. Pushing the sensitivity limit, HR-MACS identified a few metabolite signals from a single submillimeter worm at 18.8 T. However, the resultant spectral resolution was poor due to a field drift over the 10-h acquisition. Regardless, the result offered a glimpse of the possibility for a MAS study of a single tiny organism. This study also illustrated the beneficial factor of analyzing a few numbers of the organism. To avoid crowding in the cultivation progress, about 100 (or fewer) individuals are cultivated in a single culture plate; this would require 10 plates to cultivate 1000 individuals for a single NMR sample for HR-MAS. As a result, a single model study with HR-MAS would require a demanding cultivation procedure. ${ }^{85}$ On the other hand, with the possibility of analyzing a few individuals, one plate would allow 
multiple NMR samples, dramatically reducing the cultivation procedures. This was demonstrated by a discrimination analysis (OPLS-DA) of two finite C. elegans groups (wildtype vs slcf-1) with $<100$ individuals. ${ }^{77}$

One issue with HR-MACS is the fabrication of the tiny and fragile LC circuitry of the $\mu$ resonator. It demands high-precision procedures. The current effective method is manually winding, which is a labor-intensive process with zero reproductivity. To ensure the spectral reproducibility for multivariate analysis, our team introduced the use of a single $\mu$-resonator permanently fixed inside a MAS rotor and permitting a sample screening with a smaller diameter sample capillary. Two metabolomic studies with multivariate statistics have been performed with this setup, ${ }^{77,86}$ illustrating the potential in metabolomic studies. However, the constant severe spinning stress exerted onto the resonator is limited to small model studies.

Several reports have acknowledged the difficulty in assembling and reproducing the $\mu$ resonators and have attempted to apply different manufacturing approaches to ease the fabrications. Korvink and his team exploited the automation of a robotic wire-bonding technology to wind an $\mu$-solenoid and bind to a capacitor chip. They denoted the resonator as on-chip MACS. ${ }^{75}$ The fabrication process is carried out entirely by a robotic wire-bonding apparatus, enabling to produce100 on-chip MACS resonators in a single procedure. However, the reported NMR linewidth was highly inadequate, with about $1 \mathrm{ppm}$. This was due to the significant susceptibility mismatched from the gold wire $\left(\chi=-34 \times 10^{-6}\right)$ used in the wirebonding. Later, a significant improvement was made on the line-resolution, from $1 \mathrm{ppm}$ to about $0.01 \mathrm{ppm}$, by replacing the gold wire with copper, ${ }^{86}$ and thereafter, it was commercialized as Voxalytic ${ }^{\mathrm{TM}}$ MACS insert. Another MACS design, the so-called monolithic MACS, was later introduced. ${ }^{87}$ The design is based on a planar transmission-line resonator, which is self-resonant and does not require lumped-element capacitors, permitting the use of 2D MEMS printing technology. Although the manufacturing was less efficient than the wire-bonding, it offered a line resolution of about $0.1 \mathrm{ppm}$. Regardless, these studies demonstrated the possibility of mass-production of $\mu$-resonators for MACS. It is now a matter of minimizing the susceptibility mismatched with the samples to improve line resolution. 
In 2015, a new high-resolution standard microcoil probe was introduced, ${ }^{78}$ denoted as HR$\mu$ MAS. Unlike the spinning microcoil in HR-MACS, the new probe consists of a solenoid with 1-mm in diameter incorporated inside the MAS stator with a $490 \mathrm{~nL}$ sampling volume. A few probe components near the sampling volume were of significant concern in the probe design to retain the high-resolution spectra. For example, to reduce the induced $B_{z}$ fields, the microcoil is wound with a zero-susceptibility wire $(\mathrm{Cu} / \mathrm{Al})$, the air-bearings are made of a susceptibility-matched Vespel $\left(\chi=-9.2 \times 10^{-6}\right)$, similarly the entire stator structure is made with Kel-F $\left(\chi=-11.6 \times 10^{-6}\right)$. As shown in Figure 5, these modifications have significantly improved the linewidth at 50\% height (FWHM), but it also exhibits a significant skew line at $1 \%$ height. Based on a numerical field map simulation, the skew line is ascribed from the two Vespel air-bearings inside the Kel-F stator generating a strong unwanted quadratic field to the sample volume. ${ }^{88}$ To overcome this, a pair of passive ferro-shim was strategically integrated inside the probehead (Figure 5) to offset the unwanted field and supplement additional shim field equivalent to the active shim field of $B_{x^{2}-y^{2}}$, which in turn produces a quadratic field at magic-angle $B_{z^{2}}^{M A S}$

$$
B_{z^{2}}^{M A S}=B_{x^{2}-y^{2}}-2 \sqrt{2} B_{z y}
$$

where $B_{x^{2}-y^{2}}$ and $B_{z y}$ are the harmonic field functions in the active NMR shims. This implementation has suppressed the unwanted perturbed fields and yielded high-resolution spectra.

In contrast to HR-MACS, HR- $\mathrm{MAS}$ is a highly versatile and robust probe with the feasibility of heteronuclear experiments. ${ }^{1} \mathrm{H}-{ }^{13} \mathrm{C}$ HMQC experiment has been performed to profile the lactate and its brain physiological metabolism from a $300 \mu \mathrm{g}$ brain tissue extracted from a rat model previously infused with $\left[3-{ }^{13} \mathrm{C}\right]$ lactate during a brain simulation. Despite the long acquisition ( $27 \mathrm{hr}$ ), a few metabolites (alanine, lactate, glutamate, glutamine, and $\gamma$-aminobutyric acid) were identified as the relevant brain lactate metabolism accordant with those found in a previous HR-MAS study. ${ }^{89}$

The first complete study of NMR-based metabolomics with the HR- $\mu$ MAS probe was carried out on a $\sim 300 \mu \mathrm{g}$ tissue sampling of Allium sativum (garlic, Figure 6).${ }^{79}$ This study highlights a significant ex vivo NMR application with small size sampling. It enables the investigation of small anatomical regions that would be impractical with mg-scale sampling using HR- 
cycloallicin, has been identified in the two small sub-tissue anatomies (sprout and inner epidermis) inside the garlic core.

A subsequent study explored the potential of rodent tissue biopsy by spatially profiling across a coronal brain slice of C6 gliomas bearing. ${ }^{81}$ Figure 7 shows that with the same acquisition time, 13-min, the resultant line resolution of HR- $\mu \mathrm{MAS}$ is on par with that of HR-MAS; but with nearly 30 -fold less in the tissue mass. In addition, the high-resolution spectra data permit unambiguous identification of the NMR markers of C6 gliomas in the rat models. The small sampling mass permitted a systematic metabolic mapping across the brain slice with a volume voxel of $1 \times 1 \times 3 \mathrm{~mm}^{3}$, rendering a delineation of the tumor lesion using a linear PLS regression and a semi-quantification analysis. Thus, the study presents a unique ex vivo NMR possibility for analyzing pathological tissue. Another aspect worth noting is that it applied a high number of sampling data (nearly a 100-sample) in the model study, illustrating the

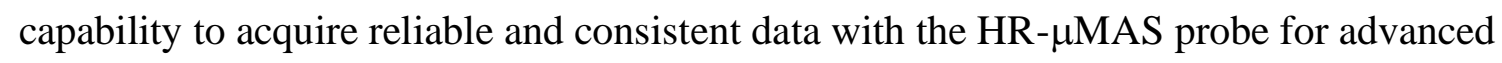
multivariate statistics. Indeed, this is imperative for metabolomic studies. Note that this large sampling model would not be possible with the previously discussed spinning $\mu$-resonator probe.

\section{Future prospects}

540 Although advancements have been made on the high-resolution standard microcoil MAS probe, it has yet to be widely applied in metabolomics. This is mainly due to the lack of feasibility. The main challenge lies mainly in the minuscule sample, which limits detection sensitivity and sample preparation. Further developments are necessary to continue striving forward to a level of application on par with the conventional HR-MAS NMR spectroscopy.

Technical developments. It should be noted that the current state of the microcoil is close to achieving the limit for detection sensitivity. Further improvement by orders of magnitude is not expected through $B_{1} / i$. Therefore, higher sensitivity would be achieved by incorporating other enhancement schemes. As discussed previously, high magnetic fields would enhance the sensitivity, but at the expense of the equipment and its running cost; moreover, it would also increase the susceptibility broadening ascribed to the microcoil. Increasing the signalaveraging would also increase the sensitivity by a factor of $\sqrt{ }_{\text {scan, but }}$ it could demand an unrealistic acquisition period. Hyperpolarization techniques could be a possible route, but 
how to incorporate the respective strategies is not apparent. Cryoprobe technology is probably the most viable; the main issue is implanting a thermal barrier between the cold $\mu$ coil and the ambient sample, complicated by the MAS stator. The piggyback concept ${ }^{17}$ could offer a possible solution where the stator is segregated from both the microcoil and the sample and could ease the implementation of an isolated cold coil. Moreover, the sample is no longer constrained inside a rotor, allowing an elongated sampling volume that renders a long ellipsoid field to facilitate the field shimming. The segregation of the sample from the stator could also offer a more feasible solution to the NMR-sample preparation.

Sample preparation is a critical component in all bioanalytical methods. Standardized protocols are necessary and have been well-established in most ex vivo NMR-based applications. ${ }^{90-92}$ This is not the case for microcoil MAS. Sample preparation for the NMR analysis may seem trivial at first glance, but it is, in fact, a strenuous task for handling specimens at a minuscule level. One must consider the entire procedure clean and quick for preserving the sample integrity. The necessity of using a $\mu$-size sample-holder requires a filling procedure that can be strenuous. The current most efficient methods are simply using a micro-pipette for the solution and sampling punch for tissue with a centrifuge, ${ }^{93}$ but these procedures are slow and demanding. Acknowledging the difficulty, the use of sampling glass capillary has been proposed for the spinning resonator HR-MACS ${ }^{77}$ and the HR- $\mu \mathrm{MAS}$ probe. ${ }^{94}$ The advantage is that it permits the NMR-sample preparation outside the rotor, simplifying the sample filling procedure. The trade-off is the loss of sensitivity with a reduced coil filling factor that can be down to $50 \%$ depending on the capillary thickness. Disposable Kel-F rotor (similar concept to the Bruker Kel-F bioinsert) has also been considered for HR- $\mu$ MAS probe, ${ }^{78,94}$ but the fragility of the small plastic rotor has hindered a rapid preparation. Indeed, further improvement is essential for a more feasible analysis with the microcoil probe. This may require new devices, such as microfluidic, for simplifying the sample filling or even an entirely new design of the microcoil probe that can facilitate the entire preparation. For example, one could consider the piggyback design, ${ }^{17}$ in which the sample tube is segregated from the rotor and could be manipulated or coupled with external sample-filling apparatus.

Possible applications. The prime advantage of microcoil MAS probes is that it opens the possibility of analyzing samples with limited availabilities. These can be biospecimens such 
as tissue biopsies, cells, organisms, or aggregated biomolecules, and they can also be nonbiosamples such as polymeric resins. It offers the investigations of a specific phenotype in isogenic specimens that would be impractical with HR-MAS because of the difficulty of isolating a sufficient quantity of the target specimens. For example, in the cell biology field, 'HR' standard microcoil MAS would be able to explore the metabolomes in target cell-type, an emerging research area in mass spectrometry that can provide a fundamental prerequisite metabolic information for understanding the underlying functions and activities. Unlike cell culture, isolating the target cell type directly from an animal is a daunting task; it relies on specific cell sorting techniques, which often hinder the collection of large quantities necessary for the profiling with HR-MAS. For example, profiling the isolated neuron and astrocyte cells may help yield insights into the fundamental of intercellular metabolic cooperation between neurons and astrocytes to further understand brain metabolism. ${ }^{95}$

Another advantage is the possibility of analyzing tiny spatial tissue regions, allowing a direct characterization of the metabolite in question that can be concealed in large sampling tissue mass. For example, a recent ex vivo HR-MAS study ${ }^{96}$ of epilepsy with a kainate-injected epileptic mouse model reported an increased $\gamma$-aminobutyric acid (GABA) level in the entire ipsilateral anterior region of the hippocampus, eliciting the relevancy of GABA as a biomarker of the epileptogenic zone. However, the extensive sampling tissue mass (5 mg) made it impossible to delineate further the epileptic zone within the region. Figure 8 shows an example of benefiting the small spatial analysis (with $\sim 150 \mu \mathrm{g}$ sampling) using the HR$\mu \mathrm{MAS}$ probe; it reveals an increased level of GABA in a tiny subregion (dentate gyrus) of the ipsilateral anterior hippocampus, pinpointing the epileptic location. Although the result needs further confirmation, it illustrates the underlying benefit of $\mu \mathrm{g}$ sampling over the $\mathrm{mg}$ scale.

612 In health science, small sample analysis could be used as a complementary approach to

613 advanced imaging techniques for enhancing the recognition of the modified metabolic

614 patterns of the disease in tissue. The potential of firsthand monitoring of the perturbations in 615 metabolic responses of the diseases could offer a practical and immediate treatment, opening 616 the possibility in clinical NMR spectroscopy, a concept proposed by Nicholson. ${ }^{97}$ Moreover, 617 the current gold standard in clinical tissue assessment is histopathology. When the tissue 618 mass is limited in a single biopsy, the mg tissue analysis with HR-MAS can be complicated 619 as it can compromise the histopathological assessments; but this would not be the case with 
microcoil MAS. In addition, the excision of $\mu \mathrm{g}$ tissue from a human patient or animal could reduce surgical invasiveness and permit longitudinal studies.

623 In agricultural science, the analysis with $\mu$ g samples could provide direct insights into the

624 integration and regulation of plant metabolism: from a single seed to a grown plant. For

625 example, the germination process in a seed is complex and of great importance for

626 developing the plant seeds to form a new individual. To characterize the metabolic

627 coordination of the distinct small regions in a seed could help the development of germination ${ }^{98}$ and essentially the plant growth. This could benefit from a spatiotemporal analysis on a single seed.

630

\section{Conclusion}

632 The recent developments of high-resolution standard microcoil MAS probe technology have offered the opportunity for opening new applications in the ex vivo platform of NMR-based metabolomics. However, there is no question that further improvements in NMR sensitivity and sample preparation are necessary for routine analysis of $\mu \mathrm{g}$ specimens and venture into clinical NMR spectroscopy. We are convinced that 'HR'- $\mu$ MAS NMR analysis could become an important component in the omics research, but this would take a collaborative effort among the different disciplines with complementary expertise to continue advancing and making high-resolution standard microcoil MAS a real possibility in metabolomics and omics in general.

641

642 Funding: The developments presented here are supported by Agence Nationale de la

643 Recherche in France (ANR-16-CE11-0023 and ANR-12-JSV5-0005)

644 Acknowledgments: I would like to acknowledge the undivided supports from all 645 collaborators, including JEOL Resonance Inc. on the HR- $\mu$ MAS probe. Dr Florence Fauvelle 646 (GIN, France) is also acknowledged for the preliminary unpublished results on the epilepsy 647 tissue in Figure 8.

648 Conflicts of Interest: The authors declare no conflict of interest.

649 Data availability: All of our works present in the review are available from the 650 corresponding author upon reasonable request. 
654 Figure 1. (a) Magnetic dipole field $B_{z}$ at point $\mathrm{P}$ of the sample ( $\left.\mu_{\text {sample }}\right)$ region outside of a magnetized sphere ( $\mu$ sphere), of which it has a radius of 'a' and a dipolar magnetic moment $\mathrm{m}$ induced by the external NMR field $B_{0} . \delta$ is the angle between $B_{0}$ and the dipolar vector $\mathrm{D}_{\mathrm{r}}$, which depends on a distance $\mathrm{r}$ between $\mathrm{m}$ and P. (b) The MAS effect, where $\delta$ becomes a time-dependent component $\delta(\mathrm{t})$ with a magic-angle $\theta_{\mathrm{MA}}=54.74^{\circ}$, and $\beta$ is the angle between the direction of the rotation axis and $\mathrm{D}_{\mathrm{r}}$ and $\phi$ is the azimuth angle characterizing the position of a magnetic moment $\mathrm{m}$ in a plane perpendicular to the rotation axis.

Figure 2. ${ }^{1} \mathrm{H}$ spectral comparison of sucrose in $\mathrm{D}_{2} \mathrm{O}$ at $11.7 \mathrm{~T}$ between solid-state MAS probes and high-resolution capable MAS probes. The arrow depicts the development toward high spectral resolution capable without forfeiting the detection sensitivity.

Figure 3. (a) ${ }^{1} \mathrm{H}$ doublet of an anomeric proton in sucrose, illustrating the loss of line resolution as the MAS frequency increases with a spinning resonator HR-MACS. (b) A summary of the FWMH in (a) and its estimated heat dissipation. The employed spinning resonator was constructed with a $30-\mu \mathrm{m}$ cross-section $\mathrm{Cu}$ wire. Adapted with permission from ref 76. Copyright 2013 American Chemical Society. Note that the temperature dependence on the chemical shift of the anomeric proton has also been observed in HRMAS. ${ }^{83}$

Figure 4. ${ }^{1} \mathrm{H}$ spectral comparison at $18.8 \mathrm{~T}$ between HR-MACS and HR-MAS of C. elegans. Despite a drastic reduction of the worm individuals in HR-MACS, the chemical shift expansion showcases the detailed similarity in the resonance profile. Adapted with permission from ref 77. Copyright 2014 American Chemical Society.

Figure 5. (a) Improvement of the line resolution with a pair of passive ferro shims mounted near the MAS stator. The ${ }^{1} \mathrm{H}$ spectra of sucrose in $\mathrm{D}_{2} \mathrm{O}$ were acquired at $11.7 \mathrm{~T}$ spinning at $4000 \mathrm{~Hz}$. (b) The numerical field simulation results show the 1D magnetic flux profile within the active sample along the magic-angle axis ascribed by the cylindrical bearings inside the stator ( $\left.B_{\text {bearing }}\right)$, a pair of ferro-shims ( $\left.B_{\text {passive }}\right)$, and the combined effect $\left(B_{\text {sum }}\right)$. The red highlight represents the sample region along the magic-angle axis $Z^{\prime}$. Adapted with permission from ref 88. Copyright 2019 Springer Nature.

Figure 6. (a) ${ }^{1} \mathrm{H}$ spectral comparison of the different anatomical garlic regions between HRMAS and HR- $\mu$ MAS. (b) The resultant S-line plot was used to identify the metabolite variances between the garlic core's two sub-regions (sprout and inner epidermis). A result that could not be easily deduced by the large-volume sampling HR-MAS experiments. Adapted with permission from ref 79. Copyright 2018 American Chemical Society.

Figure 7. (a) ${ }^{1} \mathrm{H}$ spectral comparison of the rat brain tissue between HR-MAS and HR- $\mu$ MAS NMR at 11.7 T: black-line corresponds to HR-MAS of the tumoral (C6-glioma) lesion tissue, red and blue correspond to HR- $\mu \mathrm{MAS}$ of the tumoral and healthy tissue, respectively. The spectral amplitudes are normalized to the $\mathrm{tCr}$ resonance. Based on the total SNR (1.0-4.2 ppm), the mass-sensitivity per unit time for those acquired with HR- $\mu$ MAS is about 3 -fold higher than HR-MAS. The significant NMR-markers are annotated with arrows indicating the increased and decreased level: red corresponds to tumoral tissue and blue healthy. (b) A PCA score plot was obtained from a model study containing 90 -sampling data on brain tissue, 34 from a single healthy brain slice, and 56 from two tumor-bearing slices. The excellent quality 
parameters indicated the reliability of model data acquired by the HR- $\mu \mathrm{MAS}$ probe. (c) Resultant analytical maps: [left] PLS-regression map showing the delineation of the tumor lesion. The level of the predicted values is coded with a color scheme: red being 1 corresponds to tumoral tissue and blue being 0 to healthy tissue; [right] metabolite distribution map of tCho/NAA across the slice. Each color square in both maps is relevant to a $1 \times 1$ sampling pixel. Adapted with permission from ref 81 . Copyright 2021 John Wiley and 708 Sons.

Figure 8. Ex vivo localized ${ }^{1} \mathrm{H}$ HR- $\mu \mathrm{MAS}$ spectra of the three regions (dentate gyrus (DG) dispersion and cornu ammonis (CA1 \& 3)) in an ipsilateral anterior of the hippocampus of a kainic acid-mesiotemporal lobe epilepsy mouse model, with a sampling mass of $\sim 150 \mu \mathrm{g}$.

713 Similar to the result in Figure 7, the mass-sensitivity per unit time for HR- $\mu$ MAS is about 3714 fold higher than HR-MAS. This is an unpublished preliminary result. The spectral result 715 demonstrates the beneficiary of $\mu$ g-sampling with HR- $\mu$ MAS over mg-sampling with HR716 MAS that has concealed the spatial origin of the evaluated GABA level. 


\section{References}

720

721

722

723

724

725

726

727

728

729

730

731

732

733

734

735

736

737

738

739

740

741

742

743

744

745

746

747

748

749

750

751

752

753

754

755

756

757

1. Kaebisch E, Fuss TL, Vandergrift LA, et al. Applications of high-resolution magic angle spinning MRS in biomedical studies I-cell line and animal models. NMR Biomed 2017;e3700.

2. Dietz C, Ehret F, Palmas F, et al. Applications of high-resolution magic angle spinning MRS in biomedical studies II-human diseases. NMR Biomed 2017;e3784.

3. Lindon JC, Beckonert OP, Holmes E, Nicholson JK. High-resolution magic angle spinning NMR spectroscopy: application to biomedical studies. Prog Nucl Magn Reson Spectrosc 2009;55:79-100.

4. Sitter B, Bathen TF, Tessem M-B, Gribbestad IS. High-resolution magic angle spinning (HR-MAS) MR spectroscopy in metabolic characterization of human cancer. Prog Nucl Magn Reson Spectrosc 2009;54:239-254.

5. Bathen TF, Sitter B, Sjøbakk TE, et al. Magnetic resonance metabolomics of intact tissue a biotechnological tool in cancer diagnostics and treatment evaluation. Cancer Res 2010;70:6692-6696.

6. Somashekar BS, Kamarajan P, Danciu T, et al. Magic angle spinning NMR-based metabolic profiling of head and neck squamous cell carcinoma tissues. J Proteome Res 2011;10:5232-5241.

7. Tripathi P, Somashekar BS, Ponnusamy M, et al. HR-MAS NMR tissue metabolomic signatures cross-validated by mass spectrometry distinguish bladder cancer from benign disease. J Proteome Res 2013;12:3519-3528.

8. Bruker. Released the iProbe ${ }^{\mathrm{TM}}$ HRMAS at European Magnetic Resonance Meeting (EUROMAR), Nantes, France, 2018.

9. Van de Plas R, Yang J, Spraggins J, Caprioli RM. Image fusion of mass spectrometry and microscopy: a multimodality paradigm for molecular tissue mapping. Nat Methods 2015;12:366-372.

10. Taylor L, Fuss BA, Cheng LL. Metabolic Imaging in Humans. Topic in Magn Reson Imaging 2016;25:223-235.

11. Zhu A, Lee D, Shim Hyunsuk. Metabolic Positron Emission Tomography Imaging in Cancer Detection and Therapy Response. Semin Oncol 2011;38:55-69.

12. Markley JL, Brüschweiler R, Edison AS, et al. The future of NMR-based metabolomics. Curr Opin Biotechnol 2017;43:34-40.

13. Comi TJ, Do TD, Rubakhin SS, Sweedler JV. Categorizing cells on the basis of their chemical profiles: progress in single-cell mass spectrometry. J Am Chem Soc 2017;139:3920-3929.

14. Olson DL, Peck TL, Webb AG, et al. High-resolution microcoil ${ }^{1} \mathrm{H}$ NMR for masslimited, nanoliter-volume samples. Science 1995;270:1967-1970.

15. Kc R, Henry ID, Park GHJ, Raftery D. New solenoidal microcoil NMR probe using zero-susceptibility. Concepts Magn Reson Part B Magn Reson Eng 2010;17:13-19. 
16. Grimes JH, O'Connell TM. The application of micro-coil NMR probe technology to metabolomics of urine and serum. J Biomol NMR 2011;49:297-305.

17. Janssen H, Brinkmann A, Van Eck ERH, et al. Microcoil high-resolution magic angle spinning NMR spectroscopy. J Am Chem Soc 2006;128:8722-8723.

18. Sakellariou D, Goff G Le, Jacquinot J-F. High-resolution, high-sensitivity NMR of nanolitre anisotropic samples by coil spinning. Nature 2007;447:694-697.

19. JEOL Resonance Inc. Released a $0.75-\mathrm{mm} \mu \mathrm{MAS}$ probe. $53^{\text {rd }}$ Experimental Nuclear Magnetic Resonance Conference (ENC), Miami, USA, 2012.

20. Bruker. Released Magic Angle spinning above $100 \mathrm{kHz} .56^{\text {th }}$ Experimental Nuclear Magnetic Resonance Conference (ENC), Pacific Grove, USA, 2015.

21. Samoson A. H-MAS. J Magn Reson 2019;306:16-172.

22. Struppe J, Quinn CM, Lu M. et al. Expanding the horizons for structural analysis of fully protonated protein assemblies by NMR spectroscopy at MAS frequencies above 100 kHz. Solid State Nucl Magn Reson 2017;87:117-125.

23. Struppe J, Quinn CM, Sarkar S, et al. Ultrafast 1H MAS NMR crystallography for natural abundance pharmaceutical compounds. Mol Pharmaceutics 2020;17:674-682

24. Paepe D C-D, Stanek J, Jaudzems K, et al. Is protein deuteration beneficial for proton detected solid-state NMR at and above $100 \mathrm{kHz}$ magic-angle spinning? Solid State Nucl Magn Reson 2017;87:124-136.

25. Zhang R, Pandey MK, Nishiyama Y, Ramamoorthy A. A novel high-resolution and sensitivity-enhanced three-dimensional solid-state NMR experiment under ultrafast magic angle spinning conditions. Sci reports 2015;5:1181.

26. Zhang R, Mroue KH, Ramamoorthy A. Proton-based ultrafast magic angle spinning solid-state NMR spectroscopy. Acc Chem Res 2017;4:1105-1113.

27. Andreas LB, Jaudzems K, Stanek J, et al. Structure of fully protonated proteins by proton-detected magic-angle spinning NMR. Proc Natl Acad Sci USA 2016;113:91879192.

28. Penzel S, Oss A, Org ML, et al. Spinning faster: protein NMR at MAS frequencies up to 126 kHz. J Biomol NMR 2019;73:19-29.

29. Schubeis T, Marchand TLe, Andreas L, Pintacuda G. ${ }^{1} \mathrm{H}$ magic-angle spinning NMR evolves as a powerful new tool for membrane proteins. J Magn Reson 2018;287:140-152

30. Loquet A, Mammeri NE, Stanek J. 3D structure determination of amyloid fibrils using solid-state NMR spectroscopy. Methods 2018;138-139:26-38

31. Wong A, Jiménez B, Li X, et al. Evaluation of high resolution magic-angle coil spinning NMR spectroscopy for metabolic profiling of nanoliter tissue biopsies. Anal Chem 2012;84:3843-3848.

32. Hoult DI, Richards RE. The signal-to-noise ratio of the nuclear magnetic resonance experiment. J Magn Reson 1976;24:1969-1992. 
33. Luchinat E, Barbieri L. Cremonini M, Banci L. Protein in-cell NMR spectroscopy at 1.2 GHz. J Biomol NMR 2021;75:97-107.

34. Ardenkjaer-Larsen JH. On the present and future of dissolution-DNP. J Magn Reson. 2016;264:2-12.

35. Thankamony ASL, Wittmann JJ, Kaushik M, Corzilius B. Dynamic nuclear polarization for sensitivity enhancement in modern solid-state NMR. Prog Nucl Magn Reson Spectrosc 2017;102/103:120-195.

36. Rossini AJ, Zagdoun A, Lelli M, et al. Dynamic nuclear polarization surface enhanced NMR Spectroscopy. Acc Chem Res 2013;46:1942-1951

37. Owers-Bradley JR, Horsewill AJ, Peat DT, et al. High polarization of nuclear spins mediated by nanoparticles at millikelvin temperatures. Phys Chem Chem Phys 2013;15:10413-10417,

38. Spence MM, Rubin SM, Dimitrov IE, et al. Functionalized xenon as a biosensor. Proc Natl Acad Sci USA 2001;98:10654-10657.

39. Kuch LT. Photo-CIDNP NMR spectroscopy of amino acids and proteins. Top Curr Chem 2013;338:229-300

40. Duckett SB, Mewis RE. Application of parahydrogen induced polarization techniques in NMR spectroscopy and imaging. Acc Chem Res 2012;45:1247-1257.

41. Kovacs H, Moskau D, Spraul M. Cryogenically cooled probes - a leap in NMR technology. Prog Nucl Magn Reson Spectrosc 2005;46:131-155.

42. Brey WW, Edison AS, Nast RE, et al. Design, construction, and validation of a 1-mm triple-resonance high-temperature-superconducting probe for NMR. J Magn Reson. 2006;179:290-293.

43. Mizuno T, Hioka K, Fujioka K, Takegoshi K. Development of a magic-angle spinning nuclear magnetic resonance with a cryogenic detection system for sensitivity enhancement. Rev Sci Instrum 2008;79:044706.

44. Hassan A, Quinn CM, Struppe J, et al. Sensitivity Boosts by the CPMAS CryoProbe for Challenging Biological Assemblies. J. Magn. Reson. 2020;311:106680.

45. Staab JP, Novak GJ, Kini S, Spitzmesser JB, Entzminger G, Holte LL, Doty FD. Development of a cryo-coil HR-MAS-PFG NMR probe for high-field WB magnets. $44^{\text {th }}$ Experimental Nuclear Magnetic Resonance Conference (ENC), Savannah, 2003.

46. Webb AG. Radiofrequency microcoils in magnetic resonance. Prog Nucl Magn Reson Spectrosc 1997;31:1-42.

47. Minard KR, Wind RA. Solenoidal microcoil design-Part I: optimizing rf homogeneity and coil dimensions. Concepts Magn Reson 2001;13:128-142.

48. Minard KR, Wind RA. Solenoidal microcoil design-Part II: optimizing winding parameters for maximum signal-to-noise performance. Concepts Magn Reson 2001;13:190-210. 
49. Wu N, Peck TL, Webb AG, et al. ${ }^{1} \mathrm{H}-\mathrm{NMR}$ spectroscopy on the nanoliter scale for static and on-line measurements. Anal Chem 1994;66:3849-3857.

50. Webb AG. Microcoil nuclear magnetic resonance spectroscopy. J Pharm Biomed Anal 2005;38:892-903.

51. Schroeder FC, Gronquist M. Extending the scope of NMR spectroscopy with microcoil probes. Angew Chem Int Ed 2006;45:7122-7131.

52. Kentgens AP, Bart J, van Bentum PJ, et al. High-resolution liquid- and solid-state nuclear magnetic resonance of nanoliter sample volumes using microcoil detectors. $J$ Chem Phys 2008;128:052202.

53. Fratila RM, Velders AH. Small-volume nuclear magnetic resonance spectroscopy, Annu Rev Anal Chem 2011;4:227-249.

54. Webb AG. Radiofrequency microcoils for magnetic resonance imaging and spectroscopy. J Magn Reson 2013;229:55-66.

55. Badilita V, Meier RCh, Spengler N, et al. Microscale nuclear magnetic resonance : a tool for soft matter research. Soft Matter 2012;8:10583-10597

56. Korvink JG, MacKinnon N, Badilita V, Jouda M. "Small is beautiful" in NMR. J Magn Reson 2019;306:112-177.

57. Webb AG. Nuclear magnetic resonance coupled microseparations. Magn Reson Chem 2005;43:688-696.

58. Lee, H, Yoon T-J, Figueiredo J-L, Swirski FK, Weissleder R. Rapid detection and profiling of cancer cells in fine-needle aspirates, Proc Natl Acad Sci USA 2009;106:12459-12464.

59. Jeong S, Eskandari R, Park SM, et al. Real-time quantitative analysis of metabolic flux in live cells using a hyperpolarized micromagnetic resonance spectrometer. $S c i A d v$ 2017;3:e1700341.

60. Schlotterbeck G, Ross A, Hochstrasser R, et al. High-resolution capillary tube NMR. A miniaturized 5- $\mu \mathrm{L}$ high-sensitivity TXI probe for mass-limited samples, off-line LC NMR, and HT NMR. Anal Chem 2002;74:4464-4471.

61. Edmond DT, Wormald MR. Theory of resonance in magnetically inhomogeneous specimens and some useful calculations. J Magn Reson 1988;77:223-232.

62. Yablonsky DA, Haacke EM. Theory of NMR signal behavior in magnetically inhomogeneous tissues: the static dephasing regime. Magn Reson Med 1994;32:749-763.

63. Webb AG, Grant SC. Signal-to-noise and magnetic susceptibility trade-offs in solenoidal microcoils for NMR. J Magn Reson B 1996;113:83-87.

64. Soffe N, Boyd J, Leonard M. The construction of a high-resolution $750 \mathrm{MHz}$ probehead. J Magn Reson A 1995;116:117-121.

65. Zelaya FO, Crozier S, Dodd S, McKenna R, Doddrell DM. Measurement and compensation of field inhomogeneities caused by differences in magneticsusceptibility. J Magn Reson A 1995;115:131-136. 
66. Takeda K, Takasaki T, Takegoshi K. Susceptibility cancellation of a microcoil wound with a paramagnetic-liquid-filled copper capillary. J Magn Reson 2015;258:1-5.

67. De Zanche N, Barmet C, Nordmeyer-Massner JA, Pruessmann KP. NMR probes for measuring magnetic fields and field dynamics in MR systems. Magn Reson Med 2008;60:176-186.

68. Kc R, Gowda YN, Djukovic D, et al. Susceptibility-matched plugs for microcoil NMR probes. J Magn Reson 2010;205:63-68.

69. Garroway AN. Magic-angle sample spinning of liquids. J Magn Reson 1982;49:168-171.

70. Barbara TM. Cylindrical demagnetization fields and microprobe design in highresolution NMR. J Magn Reson A 1994;109:265-269.

71. Doty FD, Entzminger G, Yang AY. Magnetism in high-resolution NMR probe design. II: HR-MAS. Concepts Magn Reson 1998;10:239-260.

72. Lippens G, Bourdonneau M, Dhalluin C, et al. Study of compounds attached to solid supports using high resolution magic angle spinning NMR. Current Org Chem 1999;3:147-169.

73. Feng J, Hu J, Burton SD, Hoyt DW. High resolution magic angle spinning ${ }^{1} \mathrm{H}$ NMR metabolic profiling of nanoliter biological tissues at high magnetic field. Chinese J Magn Reson 2013;30:1-11.

74. Wong A, Jiménez B, Li X, Holmes E, et al. Evaluation of high resolution magic-angle coil spinning NMR spectroscopy for metabolic profiling of nanoliter tissue biopsies. Anal Chem 2012;84:3843-3848.

75. Badilita V, Fassbender B, Kratt K, et al. Microfabricated inserts for magic angle coil spinning (MACS) wireless NMR spectroscopy. PLoS ONE 2012;7:1-8.

76. Wong A, Li X, Sakellariou D. Refined magic-angle coil spinning resonator for nanoliter NMR spectroscopy: enhanced spectral resolution. Anal Chem 2013;85:2021-2026.

77. Wong A, Li X, Molin L, et al. $\mu$ HR-MAS spinning NMR spectroscopy for metabolic phenotyping of Caenorhabditis elegans. Anal Chem 2014;86:6064-6070.

78. Nishiyama Y, Endo Y, Nemoto T, et al. High-resolution NMR-based metabolic detection of microgram biopsies using a 1-mm HR $\mu$ MAS probe. Analyst 2015;140:8097-8100.

79. Lucas-Torres C, Huber G, Ichikawa A, et al. HR- $\mu$ MAS NMR-based metabolomics: localized metabolic profiling of a garlic clove with $\mu \mathrm{g}$ tissues. Anal Chem 2018:90:13736-13743.

80. Adhikari SS, Zhao L, Dickmeis T, et al. Inductively coupled magic angle spinning microresonators benchmarked for high-resolution single embryo metabolomic profiling. Analyst 2019;144:7192-7199.

81. Lucas-Torres C, Roumes H, Bouchaud V, Bouzier-Sore A-K, Wong A. Metabolic NMR mapping with microgram tissue biopsy. NMR Biomed 2012;34:e4477. 
82. Aguiar PM, Jacquinot J-F, Sakellariou D. Exper-imental and numerical examination of eddy (Foucault) currents in rotating micro-coils: generation of heat and its impact on sample temperatures. J Magn Reson 2009;200:6-14.

83. Piotto M, Elbayed K, Wieruszeshi J-M, Lippens G. Practical aspects of shimming a high resolution magic angle spinning probe. J Magn Reson 2005;173:84-89.

84. Wishart DS, Bigam CG, Yao J, et al. ${ }^{1} \mathrm{H},{ }^{13} \mathrm{C}$ and ${ }^{15} \mathrm{~N}$ chemical shift referencing in biomolecular NMR. J Biomol NMR 1995;6:135-140.

85. Pontoizeau C, Mouchiroud L, Molin L, et al. Metabolomics analysis uncovers that dietary restriction buffers metabolic changes associated with aging in Caenorhabditis elegans. J Proteome Res 2014;13:2910-2919.

86. Wong A, Boutin C, Aguiar PM. ${ }^{1} \mathrm{H}$ high resolution magic-angle coil spinning (HRMACS) $\mu$ NMR metabolic profiling of whole Saccharomyces cervisiae cells: A demonstrative study. Front Chem 2014;2:1- 7.

87. Lehmann-Horn JA, Jacquinot J-F, Ginefri JC et al. Monolithic MACS micro resonators. J Magn Reson 2016;271:46-51.

88. Nishiyama M, Lucas-Torres C, Piao R, et al. Supplemental shimming for HR- $\mu$ MAS NMR spectroscopy. Appl Magn Reson 2019;50:1305-1313.

89. Sampol D, Ostrofet E, Jobin M-L, et al. Glucose and lactate metabolism in the awake and stimulated rat: a 13C-NMR study. Front Neuroenergetics 2013;5:5.

90. Beckonert O, Coen M, Keun HC, et al. High-resolution magic-angle-spinning NMR spectroscopy for metabolic profiling of intact tissues. Nat Protoc 2010;5:1019-1032.

91. Beckonert O, Keun HC, Ebbels TMD, et al. Metabolic profiling, metabolomic and metabonomic procedures for NMR spectroscopy of urine, plasma, serum and tissue extracts. Nat Protoc 2007;2:2692-2703.

92. Kim HK, Choi YH, Verpoorte R. NMR-based metabolomic analysis of plants. Nat Protoc 2010;5:536-549.

93. Lucas-Torres C, Bernard T, Gaspard H, et al. General guidelines for sample preparation strategies in HR- $\mu$ MAS NMR-based metabolomics of microscopic specimens. Metabolites 2020;10:54.

94. Duong NT, Yamato M, Nakano M, et al. Capillary-inserted rotor design for HR $\mu$ MAS NMR-based metabolomics on mass-limited neurospheres. Molecules 2017;22:1289.

95. Allen NJ, Eroglu C. Cell biology of astrocyte-synapse interactions. Neuron 2017;96:697-708.

96. Hamelin S, Stupar V, Mazière L, et al. In vivo $\gamma$-animobutyric acid increase as a biomarker of the epileptogenic zone: an unbiased metabolomics approach. Epilepsia 2021;62:163-175.

97. Kinross JM, Holmes E, Darzi AW, Nicholson, JK. Metabolic phenotyping for monitoring surgical patients. Lancet 2011;377:1817-1819. 
98. Feenstra AD, Alexander LE, Song Z, et al. Spatial mapping and profiling of metabolite distributions during germination. Plant Physiol 2017;174:2532-2548. 
(a) Dipole field $B_{z}$

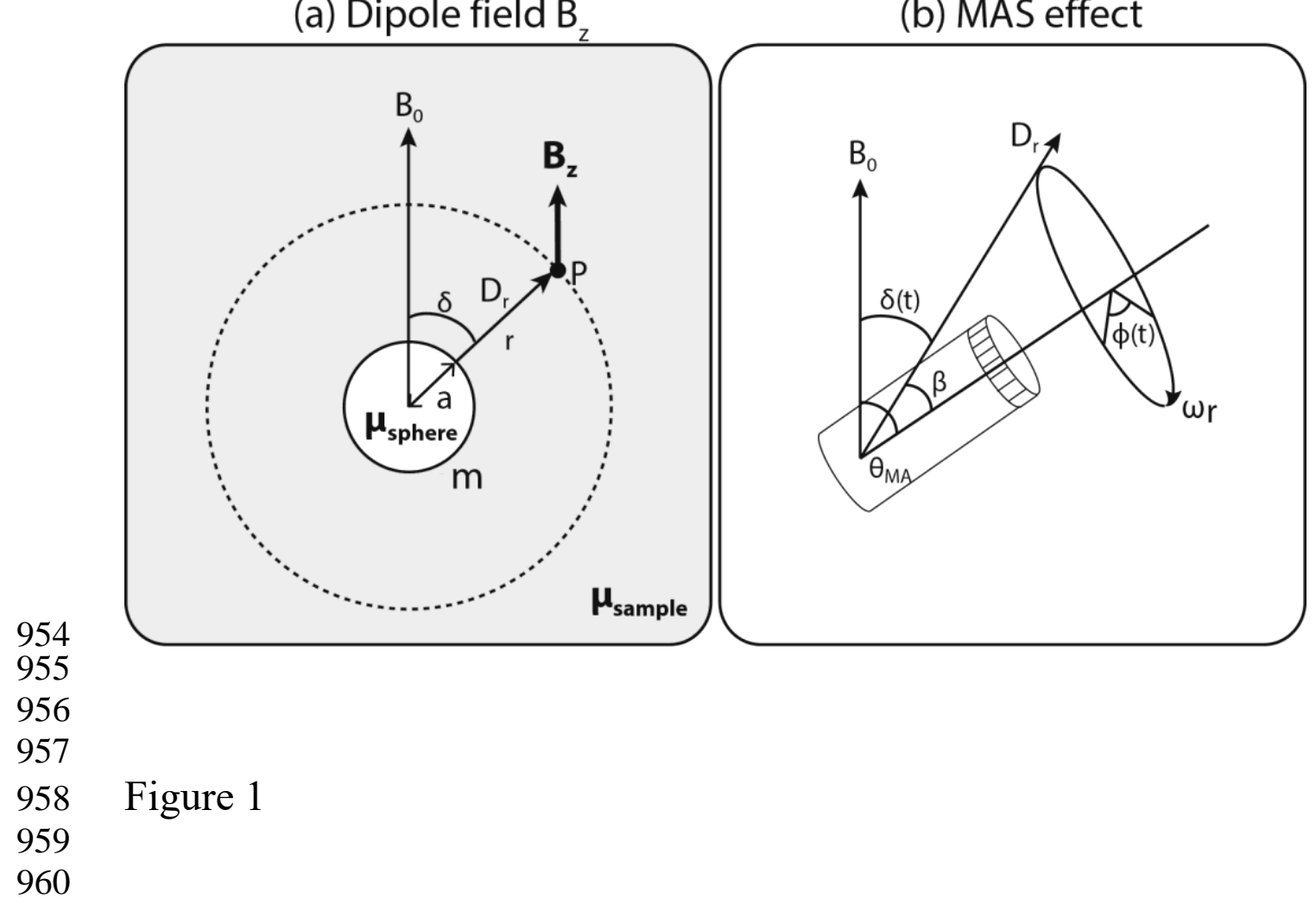


961

962

963

964

965

966

967

968

969
High-Resolution standard MAS probe

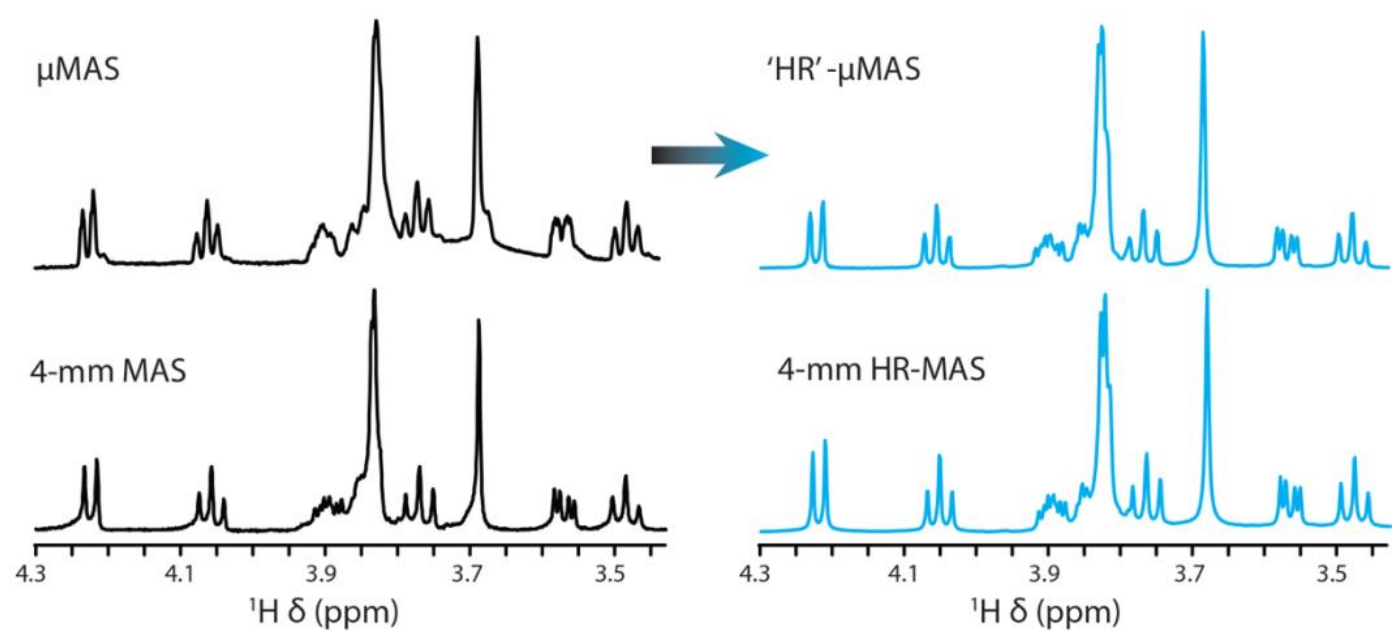

Figure 2 
(a)

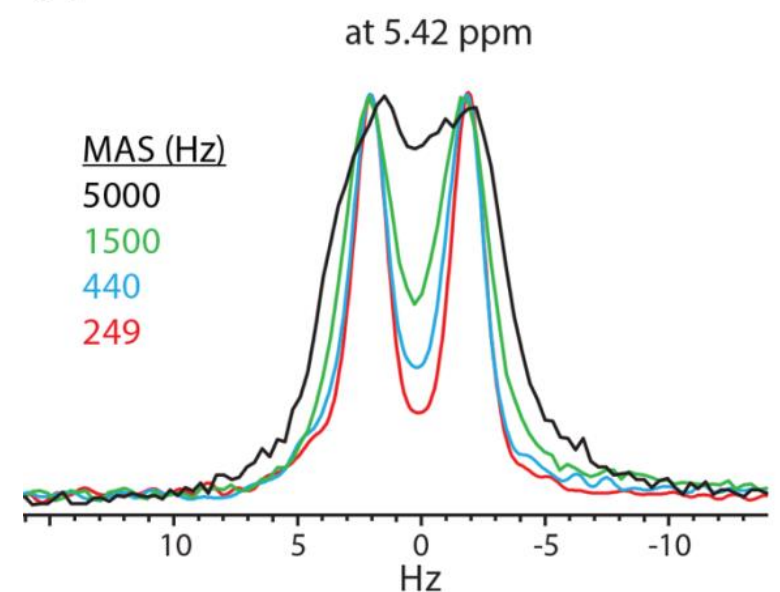

972

973

974

975

976

977

Figure 3 (b) power dissipation (nW)

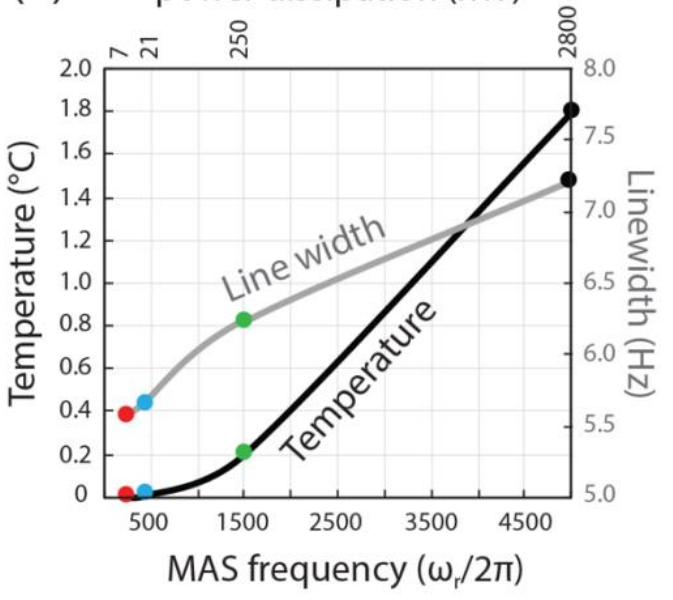




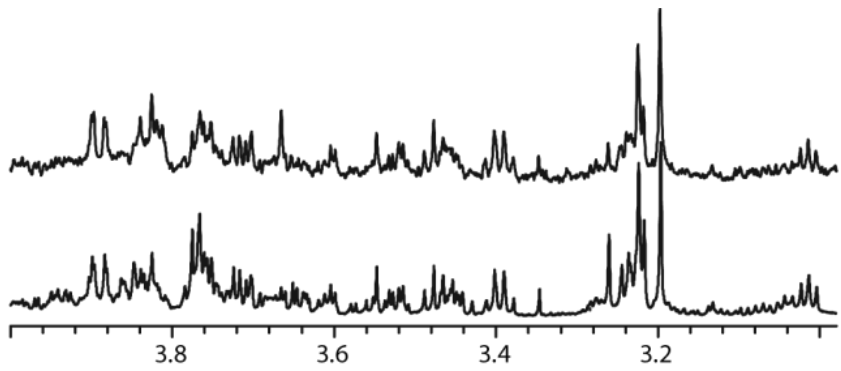

\section{0- $\mu \mathrm{m}$ HR-MACS spinning at $314 \mathrm{~Hz}$} (12 worms; 120 min)

980

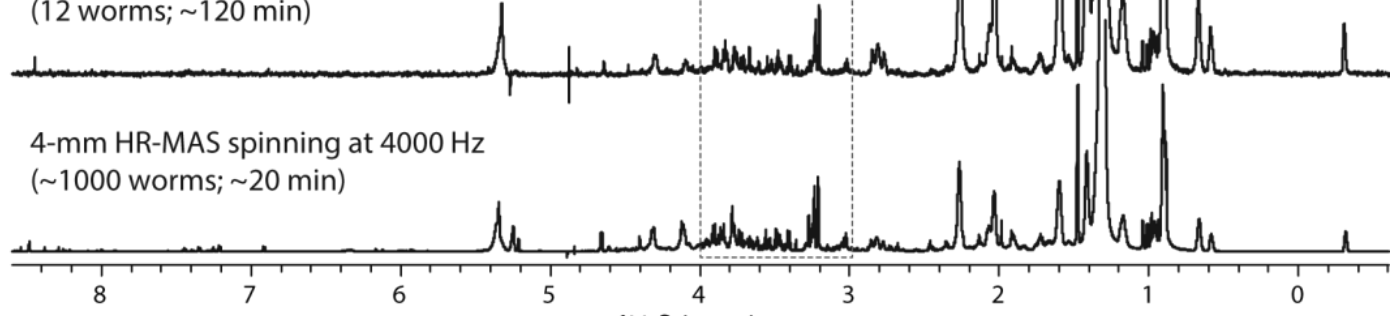

981 ${ }^{1} \mathrm{H} \delta(\mathrm{ppm})$

982

983

984

985 
(a)
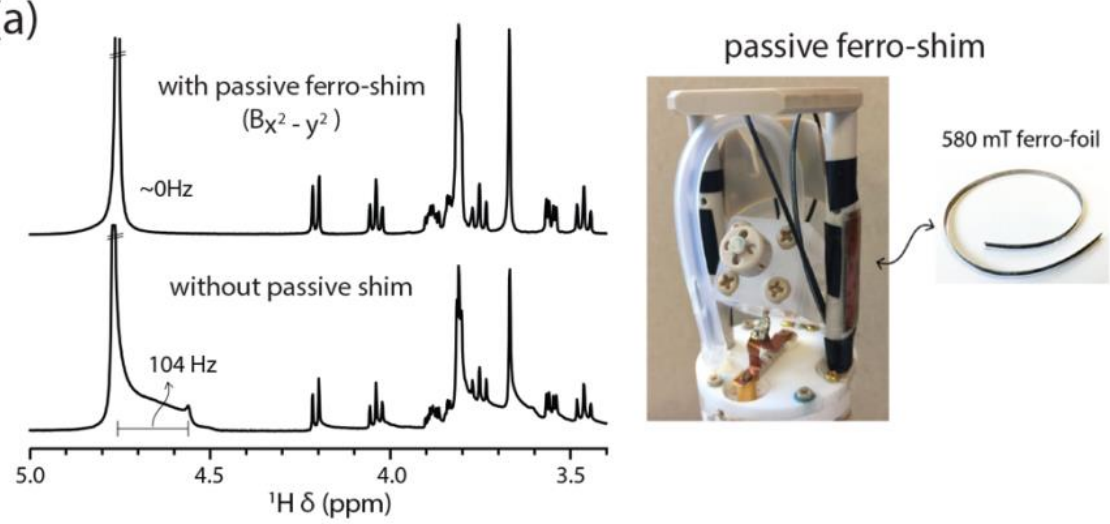

(b)
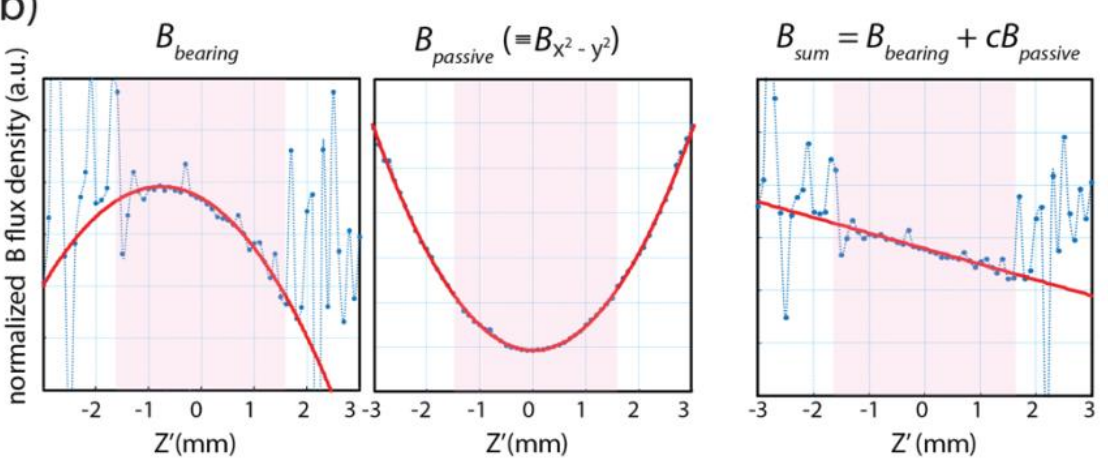

989

990

991

992

993

994

995

996 
$\begin{array}{ll}\text { (a) } & \text { HR-MAS } \\ (\sim 15 \mathrm{mg})\end{array}$
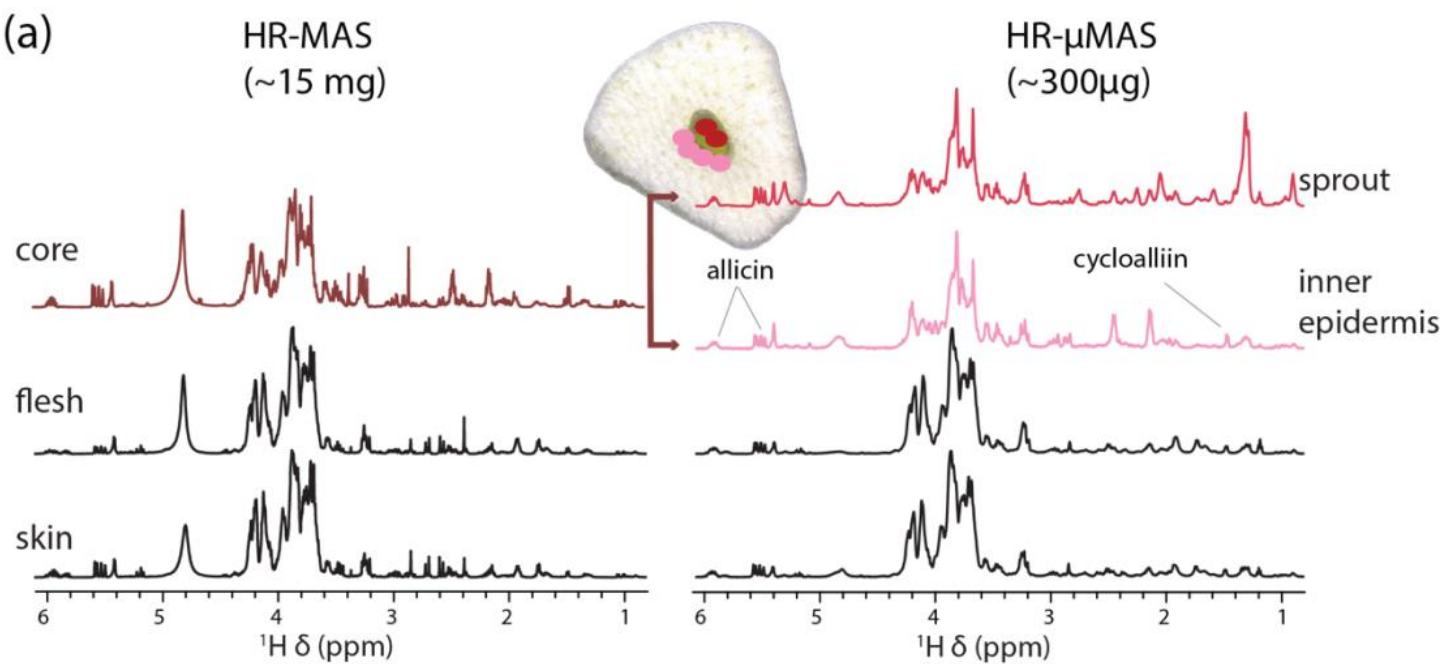

(b)

aromatic

sugar

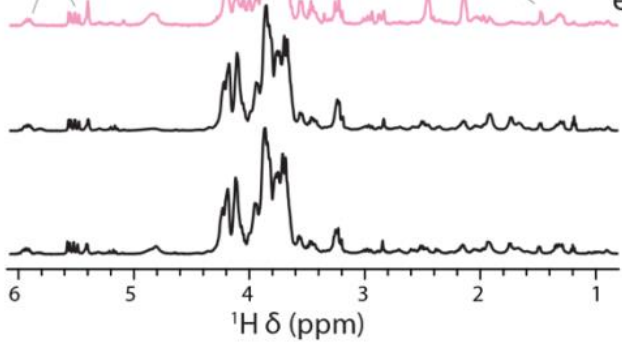

999
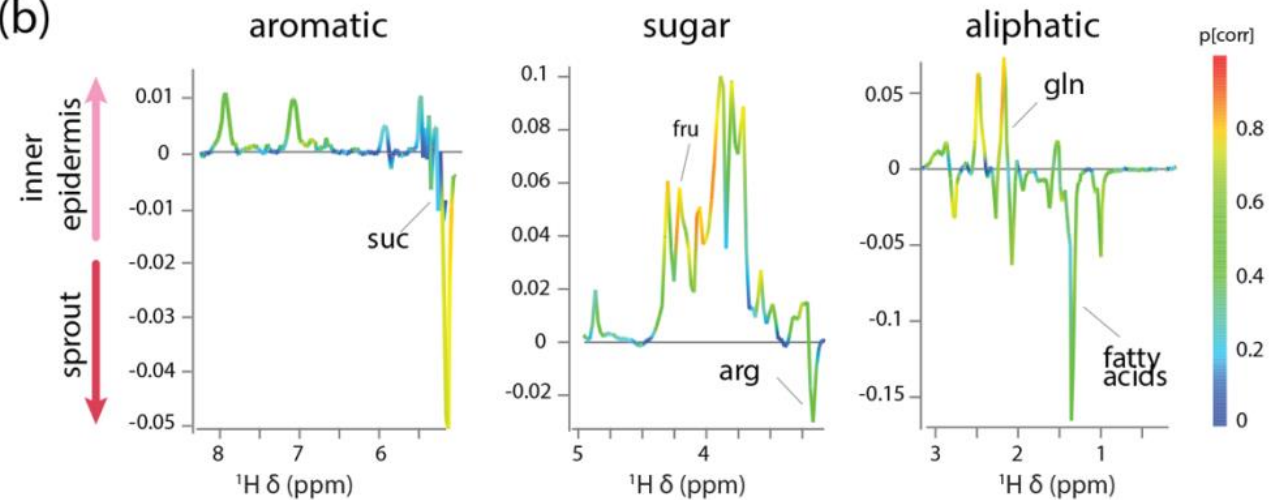

1000

1001

1002

1003

Figure 6

1004

1005 
1008

(a) $\quad \begin{aligned} & \Delta \uparrow \\ & \text { Gly }\end{aligned}$

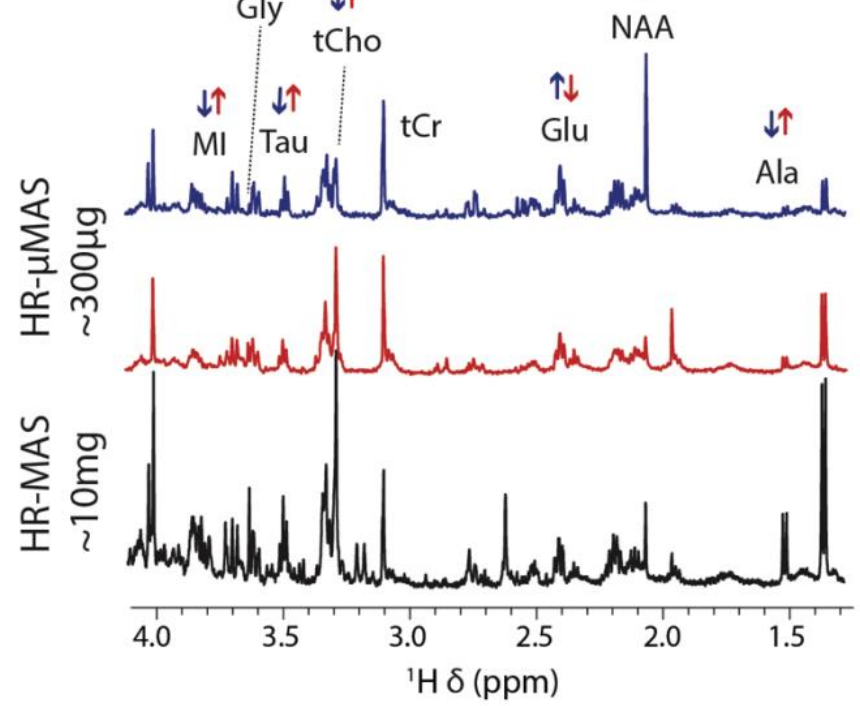

(b)

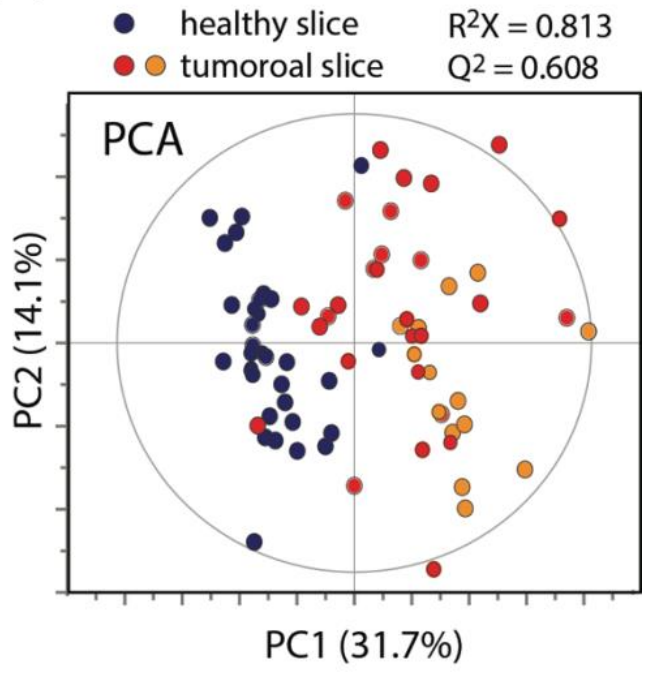

(c)

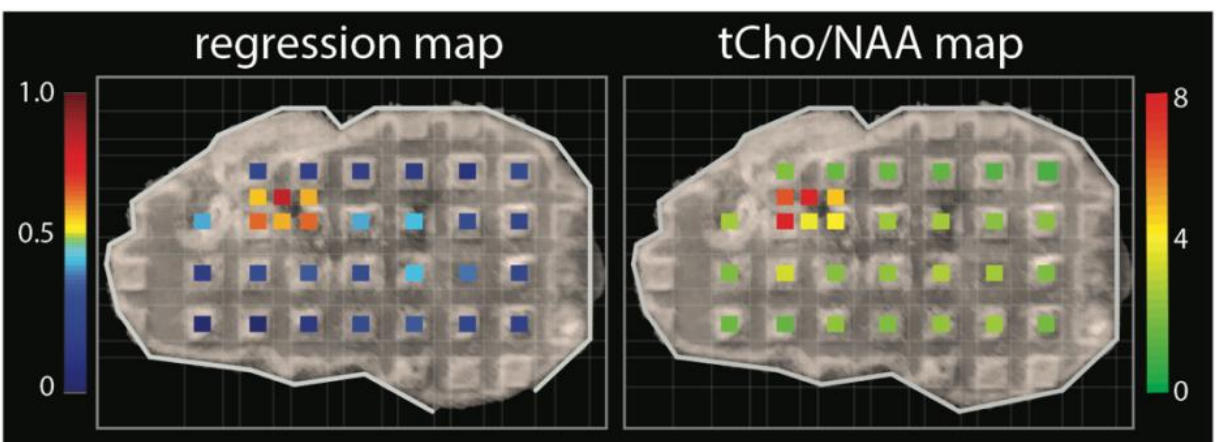

1011 Figure 7

1012

1013

1014 


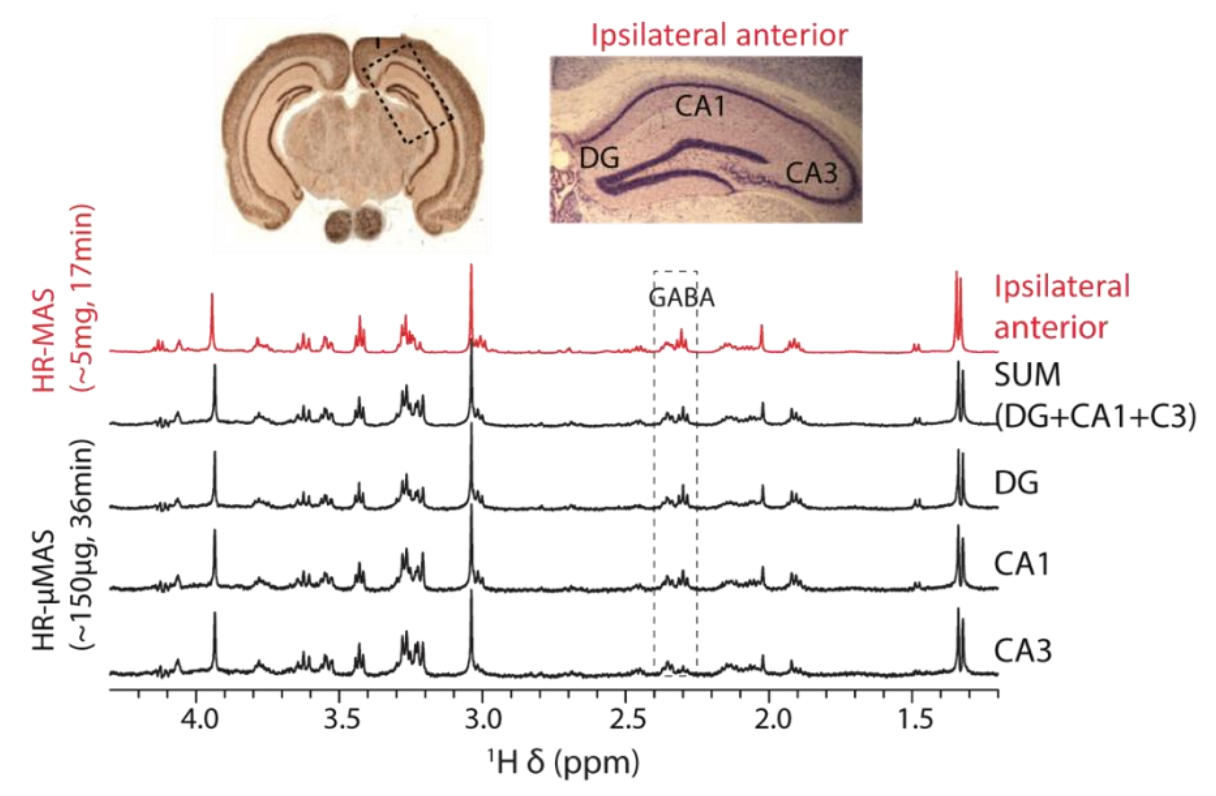

1015

1016

1017

1018

1019 Figure 8

1020

1021 